\title{
Experimental performance of latent thermal energy storage for sustainable cooling of buildings in hot-arid regions
}

\section{Rami Zeinelabdein ${ }^{1}$ ab, Siddig Omer a, and Guohui Gan a}

(a) Department of Architecture and Built Environment, Faculty of Engineering, the University of Nottingham, University Park, Nottingham NG7 2RD, UK

(b) Department of Housing Studies, Faculty of Architecture, University of Khartoum, Sudan

\section{Highlights}

- A modular PCM-air heat exchanger for free cooling of buildings has been proposed

- Narrow air flow channels result in a higher cooling potential and a faster charging process

- Thermal comfort period provided by the system during the discharging phase is not affected by the air channels height

- Inlet air temperature and flow rate have a significant impact on the PCM charging and discharging performance

\begin{abstract}
The use of phase change material (PCM) as energy storage of cooling during the night-time to be retrieved during the daytime is one of the sustainable strategies for cooling buildings. Application of this strategy in hot climates is scarce, and the majority of published work has been conducted in moderate and continental climates. Therefore, in the present work, a modular PCM-air heat exchanger appropriate for buildings application in hot-arid regions has been investigated, utilising commercial paraffin-based RT28HC PCM modules. The thermal performance of the proposed system has been investigated under various operating conditions for different PCM modules arrangements. The results confirmed that a compact TES unit with narrow air flow channels has a better thermal performance, resulting in 10-14\% reduction in the charging time, whilst this has a negligible impact on the comfort time during the discharging period. The results have shown that the proposed system is capable of operating satisfactorily under hot-arid climate conditions, and substantial energy savings are achievable.
\end{abstract}

\section{Keywords}

Thermal energy storage; Phase change material; Free cooling; Hot-arid.

\footnotetext{
${ }^{1}$ Corresponding author: Tel.: +44 7478800413; +249 918011132

E-mail address: rami.zeinelabdein@ nottingham.ac.uk; rami.zeinelabdein@uofk.edu (R. Zeinelabdein)
}

R. Zeinelabdein, 2019 


\begin{tabular}{|c|c|c|}
\hline \multicolumn{3}{|c|}{ Nomenclature } \\
\hline$A$ & area & $\mathrm{m}^{2}$ \\
\hline$C p$ & specific heat capacity & $\mathrm{kJ} / \mathrm{kg} \cdot \mathrm{K}$ \\
\hline$d t$ & temperature difference & $\mathrm{K}$ \\
\hline$d$ & thickness & $\mathrm{m}$ \\
\hline$H$ & height & $\mathrm{m}$ \\
\hline$H_{\text {channel }}$ & height of the air channel & $\mathrm{mm}$ \\
\hline$h_{\mathrm{si}}$ & heat transfer coefficients at the inside surface & $\mathrm{W} / \mathrm{m}^{2} \mathrm{~K}$ \\
\hline$h_{\text {so }}$ & heat transfer coefficients at the outside surface & $\mathrm{W} / \mathrm{m}^{2} \mathrm{~K}$ \\
\hline$L$ & length & $\mathrm{m}$ \\
\hline$\dot{m}$ & air mass flow rate & $\mathrm{kg} / \mathrm{s}$ \\
\hline$Q_{\text {air }}$ & heat transferred from the air & $\mathrm{W}$ \\
\hline$Q_{\mathrm{PCM}}$ & heat absorbed/released by the PCM & W \\
\hline$Q_{\text {exch }}$ & heat exchanged with the ambient & $\mathrm{W}$ \\
\hline$t$ & time & $\mathrm{s}$ \\
\hline$T_{\text {air,in }}$ & inlet air temperature & ${ }^{\circ} \mathrm{C}$ \\
\hline$T_{\text {air,out }}$ & outlet air temperature & ${ }^{\circ} \mathrm{C}$ \\
\hline$T_{\mathrm{amb}}$ & ambient air temperature & ${ }^{\circ} \mathrm{C}$ \\
\hline$T_{\text {surround }}$ & air temperature around the test rig & ${ }^{\circ} \mathrm{C}$ \\
\hline$T_{\mathrm{TES}}$ & temperature of the thermal energy storage & ${ }^{\circ} \mathrm{C}$ \\
\hline$U$ & thermal transmission coefficient & $\mathrm{W} / \mathrm{m}^{2} \mathrm{~K}$ \\
\hline$U_{\mathrm{x}}$ & overall uncertainty of the experiment & \\
\hline$\dot{V}$ & air volume flow rate & $\mathrm{L} / \mathrm{s}$ \\
\hline$W$ & width & $\mathrm{m}$ \\
\hline$\Delta x$ & sensitivity of the variable $x$ & \\
\hline$\lambda$ & thermal conductivity & $\mathrm{W} / \mathrm{m} \mathrm{K}$ \\
\hline \multicolumn{3}{|c|}{ Abbreviations } \\
\hline CFD & Computational Fluid Dynamics & \\
\hline HTF & Heat Transfer Fluid & \\
\hline PCM & Phase Change Material & \\
\hline TES & Thermal Energy Storage & \\
\hline \multicolumn{3}{|c|}{ Subscripts } \\
\hline air & air & \\
\hline $\mathrm{amb}$ & ambient & \\
\hline in & inlet & \\
\hline ins & insulation & \\
\hline out & outlet & \\
\hline wall & duct wall & \\
\hline \multicolumn{3}{|c|}{ Superscripts } \\
\hline . & time-step & \\
\hline
\end{tabular}




\section{Introduction}

Nowadays, conventional air conditioning systems are intensively utilised for cooling purposes, thermal comfort provision, and indoor air quality improvement in buildings [1]. These systems are accountable for most of the energy consumption in buildings, having a negative impact on the environment, and causing a considerable impact on the energy supply and demand balance $[2,3]$. Therefore, sustainable and environmentally friendly alternative strategies are vastly needed to avert or rather to reduce the operation of these conventional systems $[4,5]$.

In particular, some hot-arid regions (where a high demand for cooling in buildings) feature a small temperature variation between the day-time indoors and the night-time outdoors [6]. The natural coolness available at night hours can be introduced into the building interior using a fan to provide instant cooling and to be stored in an appropriate thermal energy storage (TES) medium for later use during the demand period. This concept is known in the literature as "the free cooling of buildings" [7]. The free cooling strategy is much applicable for locations with a diurnal temperature variation larger than $12 \mathrm{~K}[6,8]$.

TES systems play a key role in the incessant operation of the free cooling technology [9]. TES mechanisms are classified into sensible, latent and chemical storages or a combination of these [10]. Unlike sensible heat storage materials, phase change materials (PCMs) has gained growing interest worldwide as efficient lightweight TES substances for building applications [6]. PCMs have the advantage of a large energy density and possess an isothermal performance, which makes these substances appropriate for maintaining the thermal comfort day and night $[11,12]$.

The utilisation of PCM as a specialised energy storage in free cooling systems has launched since 2000 by Turnpenny et al. [13, 14]. Recent development in this technology has been reported in several published reviews [1, 15-18]. The literature revealed that the free cooling of buildings has been investigated under different climate conditions using different geometrical configurations of PCM storage. The majority of the studies were carried out considering system application in moderate and continental climates. Turnpenny et al. [13, 14] have examined a PCM-air heat exchanger utilising heat pipes embedded in cylindrical PCM modules under the UK climate. Their developed design allowed around $200 \mathrm{~W}$ heat transfer rate between the PCM and the HTF, which is sufficient for cooling demand under UK summer conditions. Studies reported in references [19-21] have assessed numerically the thermal performance of a packed-bed PCM arrangement using a cylindrical tank filled with PCM spheres under summer conditions of European climate. The model has been verified experimentally. It was concluded that PCMs with a large melting/solidification temperature range $(12 \mathrm{~K})$ are more beneficial for free cooling of buildings than PCMs with a narrow temperature range $(4 \mathrm{~K})$. The authors have pointed out that the assumed PCM temperature ranges were very large but typical for some commercially available PCM, such as that tested in their experiments (RT20 paraffin, Rubitherm). Accordingly, in the numerical model, it has been assumed that more than $90 \%$ of the latent heat concentrates on the upper half of the phase change temperature range. Mosaffa et al. [22] have studied the thermal behaviour of a TES system comprises PCMs with multiple temperature ranges for the climate of Eindhoven, 
Netherlands. An optimised TES design capable of maintaining the supply air temperature below $20{ }^{\circ} \mathrm{C}$ for around 8 hours duration was introduced. Borderon et al. [23] have evaluated the applicability of a developed free cooling system for summer comfort in four cities in France. The outcomes were varied between promising and less effectiveness based on the microclimate. The authors have reported that the system feasibility needs to be considered.

Yanbing et al. [24] have carried out an analysis for a packed-bed PCM storage system during the summer season in China. The system provided cooling discharging rates up to $1000 \mathrm{~W}$ and $300 \mathrm{~W}$ during night-time and daytime, respectively. Nagano et al. [25] have reduced the cooling load of a room under moderate summer conditions in Japan by $89 \%$ using a storage system of packed-bed PCM granules impregnated into the room floor. Takeda et al. [26] have developed the free cooling system proposed in [25] and tested it for the summer cooling of eight cities in Japan. It has been indicated that around 42.8\%-62.8\% reduction in the cooling load can be realised by the developed system. Alam et al. [27] have compared the thermal performance of a free cooling system to a system based on a ceiling-integrated PCM under summer conditions of Melbourne, Australia (a temperate oceanic climate). The authors found that the free cooling system is more efficient, achieving a reduction in room temperature by $1.8^{\circ} \mathrm{C}$ compared to 0.5 ${ }^{\circ} \mathrm{C}$ obtained by the PCM usage in the ceiling. Rajagopal et al. [28] have assessed the potential of free cooling technology in commercial buildings in Bangalore, an Indian city with a moderate/temperate climate all the year round. The findings indicated that the proposed system is able to fulfil the annual cooling load without mechanical systems operation. For the temperate climate of Bangalore city, Panchabikesan et al. [29, 30] have investigated the performance of a free cooling system incorporated a direct evaporative cooling unit under real climate conditions. A significant drop in charging time was obtained by the combined system compared to the free cooling mode only, as a result of inlet air temperature decrease based on the local relative humidity.

There are several studies conducted under Mediterranean climate conditions. Jaber and Ajib [31] have combined an indirect evaporative cooler with PCM storage for domestic application in Amman, Jordan. The authors introduced an optimised system design capable of meeting around $80 \%$ of the total cooling demand with a payback period 7.8 years. Iten and Liu [32] tested a TES system consists of flat PCM panels for free cooling of buildings in Portugal. The results have shown the important impact of the inlet air conditions on the charging and discharging characteristics.

Furthermore, there are several studies carried out utilising simulation and/or laboratory-scale experiments [6, 33-37] in which the selected PCM transition temperature and the tested operating conditions have reflected the moderate summer conditions. Overall, the results of free cooling systems application under moderate summer conditions have shown a capability of lowering buildings cooling load and limiting the operation of air conditioning systems.

The first studies exploring the concept of free cooling in hot-arid climates have been conducted in 2011 by Waqas and Kumar [38, 39], where a prototype comprises three flat plate PCM containers arranged in series was tested. The findings demonstrated that the PCM solidification was more sensitive to the inlet air temperature than the air flow rate. The developed system 
was then coupled with a solar air collector and investigated in [40] for winter heating under the composite climate of Islamabad, Pakistan. Muthuvelan et al. [41] studied the thermal performance of a PCM heat exchanger for free cooling in Pune, a city with a hot semi-arid climate in India. A $2.5 \mathrm{~K}$ reduction in the indoor air temperature was achieved. The authors reported that the system performance is only appropriate when the discharging air temperature is higher than the comfort level by $5 \mathrm{~K}$. However, the supportive air conditioning system is still required. Zeinelabdein et al. [4] evaluated numerically the feasibility of free cooling incorporating PCM under the hot-arid climate of Khartoum, Sudan, by investigating a flat-plate TES unit under various operating conditions. It was suggested a selection of PCMs with a melting temperature close or equal to the upper limit of the summer comfort to expand the charging period.

It is evident from the literature that although there are many conducted studies in the area of free cooling of buildings using PCM storage, the majority of the research focused on the technology investigation under cool, moderate, and continental climates, where there is no serious need for cooling. On the other hand, regions with a high demand for cooling reaching almost nine months a year have given less attention, and hence, published work is generally scarce. Additionally, detailed parametric analysis on the TES system geometrical configuration is still required.

In the present article, a comprehensive experimental investigation of a proposed free cooling system has been carried out. The system evaluated is based on the results of a computer simulation to predict the performance of a free cooling system in hot climates published in Zeinelabdein et al. [42]. The study aims to evaluate the charging and discharging characteristics of a modular PCM energy storage for free cooling of buildings under hot-arid climate conditions through examining the impact of the PCM stacking arrangement by varying the air flow channels and the impact of inlet operating conditions. The outcomes of this research would be useful in finding out how the above-mentioned parameters could be adjusted to produce an appropriate design of PCM-air heat exchangers applicable for real implementation in buildings under hot-arid climates. 


\section{System description}

\subsection{PCM selection}

The selection of PCM for building cooling and heating requirements has widely been considered in the literature. For free cooling of buildings, the PCM should be selected so the outlet air temperature from the system will be within the comfort zone during the discharging time, besides allowing rapid PCM solidification during the charging time [21, 24]. Thus, for the present study, the paraffin RT28HC with a transition temperature $27-29{ }^{\circ} \mathrm{C}$ produced by Rubitherm $\mathrm{GmbH}$ [43] has been selected as it possesses a phase change temperature suitable for the prevailing diurnal temperature variation in hot climates; compatible with the charging ambient air temperature and the thermal comfort range of $25.5-30{ }^{\circ} \mathrm{C}$ during summer months; has a high enthalpy of fusion. Specifications of the RT28HC PCM given by the manufacturer are presented in Table 1.

Table 1: Thermo-physical properties of the RT28HC PCM [43].

\begin{tabular}{ll}
\hline Property & Value \\
\hline Phase change temperature range & $27-29{ }^{\circ} \mathrm{C}$ \\
Heat storage capacity (latent + sensible heat between $21{ }^{\circ} \mathrm{C}$ and $36{ }^{\circ} \mathrm{C}$ ) & $250 \mathrm{~kJ} / \mathrm{kg} \pm 7.5 \%$ \\
Specific heat (both phases) & $2 \mathrm{~kJ} / \mathrm{kg} \mathrm{K}$ \\
Thermal Conductivity (both phases) & $0.2 \mathrm{~W} / \mathrm{m} \mathrm{K}$ \\
Density (solid at $15{ }^{\circ} \mathrm{C}$ ) & $880 \mathrm{~kg} / \mathrm{m}^{3}$ \\
Density (liquid at $40{ }^{\circ} \mathrm{C}$ ) & $770 \mathrm{~kg} / \mathrm{m}^{3}$ \\
Volume change & $12.5 \%$ \\
Maximum operating temperature & $50{ }^{\circ} \mathrm{C}$ \\
\hline
\end{tabular}

\subsection{Description of the TES unit}

The laboratory system for free cooling of buildings consists of an arrangement of macroencapsulated PCM modules placed inside an aluminium enclosure; an air circulating fan coupled with variable speed controller; and ducting system components such as circular ducts, divergent, convergent and regulating dampers. The compact storage modules (CSM) filled with RT28-HC PCM, which produced by Rubitherm, were used in the TES system.

The total mass of the PCM utilised was $8.8 \mathrm{~kg}$, which is sufficient to fulfil a cooling capacity of $0.616 \mathrm{kWh}$. A system with such cooling capacity can be used to partially meet the daily cooling load of a single room $\left(16 \mathrm{~m}^{2}\right)$ in a residential building in hot climates, depending on the diurnal climate conditions and the operation schedule. However, the modular design of the proposed TES unit allows high flexibility to adjust or scale-up the system capacity according to the cooling requirements. 
The proposed TES unit comprises 16 modules, filled with RT28-HC PCM, stacked horizontally over each other in eight parallel rows with two modules in each row. A rectangular aluminium enclosure was fabricated to accommodate the entire arrangement of the PCM storage modules. The PCM modules arrangement inside the main container is illustrated in Figure 1, and the geometrical parameters of the TES system are presented in Table 2.

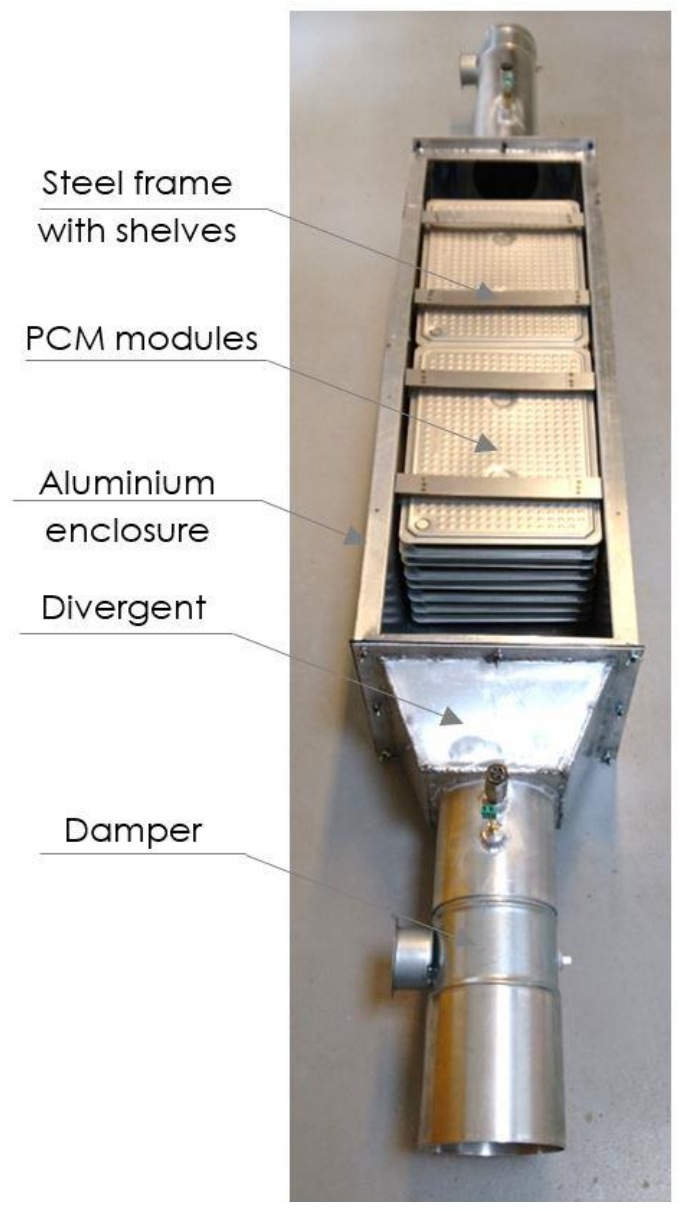

Figure 1: PCM modules arrangement.

Table 2: Geometrical parameters of the TES system.

\begin{tabular}{ll}
\hline Parameter & Value \\
\hline Dimensions of the PCM module & $0.45 \mathrm{~m}(L) \times 0.30 \mathrm{~m}(W) \times 0.01 \mathrm{~m}(H)$ \\
Thickness of the module plates & $0.48 \mathrm{~mm}$ \\
Tare weight of the module & $0.317 \mathrm{~kg}$ \\
Mass of the PCM inside a single module & $0.549 \mathrm{~kg}$ \\
Dimensions of the TES enclosure & $1.25 \mathrm{~m}(L) \times 0.31 \mathrm{~m}(W) \times 0.26 \mathrm{~m}(H)$ \\
Wall thickness of the TES enclosure & $6.0 \mathrm{~mm}$ \\
Total weight of the PCM in the TES unit & $8.8 \mathrm{~kg}$ \\
Number of PCM modules in the TES unit & $16 \mathrm{modules}$ \\
\hline
\end{tabular}


In the present study, both mass and thickness of the PCM were kept constant in all case studies while the height of air passages between the PCM modules was varied in order to understand the impact of the TES compactness on the system thermal performance. Three different air channels heights were 10, 15, and $20 \mathrm{~mm}$ considered, and thus, three stainless steel supporting frames with shelves were constructed (Figure 2a). In the structures with air channels height 10 and $15 \mathrm{~mm}$, the PCM modules were placed in the middle of the main duct and rigid insulation boards of $22.5 \mathrm{~mm}$ and $45.0 \mathrm{~mm}$ thick, respectively, were used at the top and bottom sides of the main duct to fill the remaining interior space (Figure $2 b$ ). The entire rig was thermally insulated to reduce the heat exchange with the surrounding environment. A $50 \mathrm{~mm}$ thick rigid polyisocyanurate foam insulation of a thermal conductivity $0.022 \mathrm{~W} / \mathrm{m} \mathrm{K}$ was used all around the TES unit.

(a)
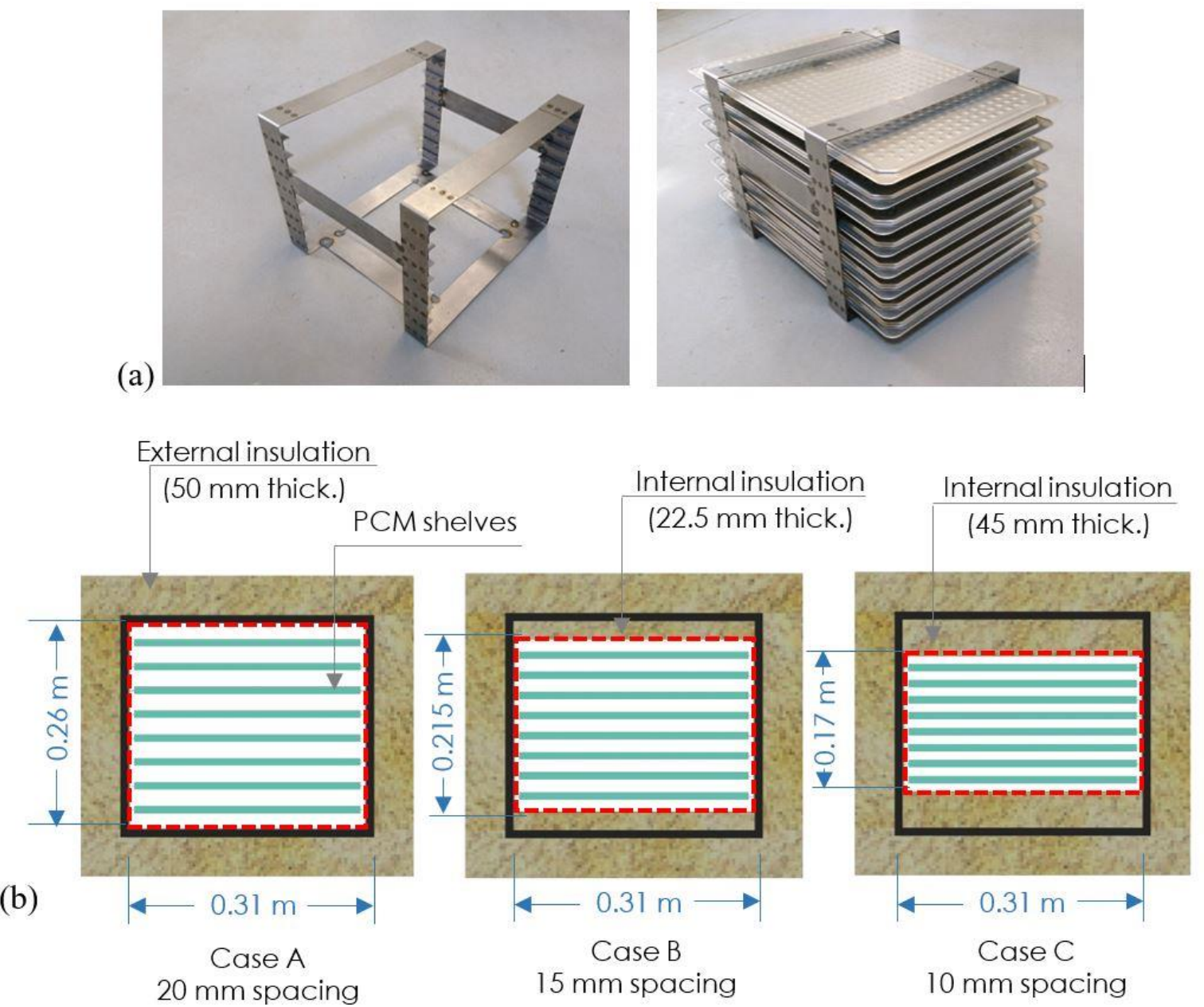

Figure 2: (a) Photographs of the stainless steel supporting frame with PCM shelves; (b) Details of the three tested PCM modules arrangements. 


\section{Methodology}

\subsection{Climate conditions}

Microclimate plays a key role in the application of free cooling strategies in buildings [42]. In this study, Khartoum city, the capital of Sudan, has been selected as a location representing the hot regions. Khartoum is located at a latitude of $15^{\circ} 6^{\prime} \mathrm{N}$ and a longitude of $32^{\circ} 55^{\prime} \mathrm{E}$ [44]. According to Köppen-Geiger climate classification, Khartoum climate can be classified as a hot arid, with a long dry season extending for nine months from October to June, and a rainy season from July to September [45].

The monthly outdoor temperature and the precipitation rates recorded during the period 19712010 by Khartoum airport meteorological station are presented in Figure 3 [46]. Khartoum climate is characterised by a very hot summer, where average temperatures routinely exceed $40{ }^{\circ} \mathrm{C}$ in peak summer months (April-June), and a warm dry winter (November-February) with relatively cool nights with temperatures just above $15^{\circ} \mathrm{C}$. Several previous studies $[6,8]$ have indicated that a diurnal temperature variation higher than $12 \mathrm{~K}$ is the most appropriate for free cooling application in buildings. This represents the case for Khartoum where the diurnal temperature variation exceeds $12 \mathrm{~K}$ most of the year as shown in Figure 3.

In the current experiments, since ambient air is used to cool the PCM, the inlet temperatures during the charging process were selected based on the prevailing nocturnal temperatures during summer and transitional months in Khartoum (March-October). For the discharging process, the air temperatures have been selected based on the daytime ambient conditions and in the case of circulating the indoor air through the system based on published data by the authors in a previous study [42].

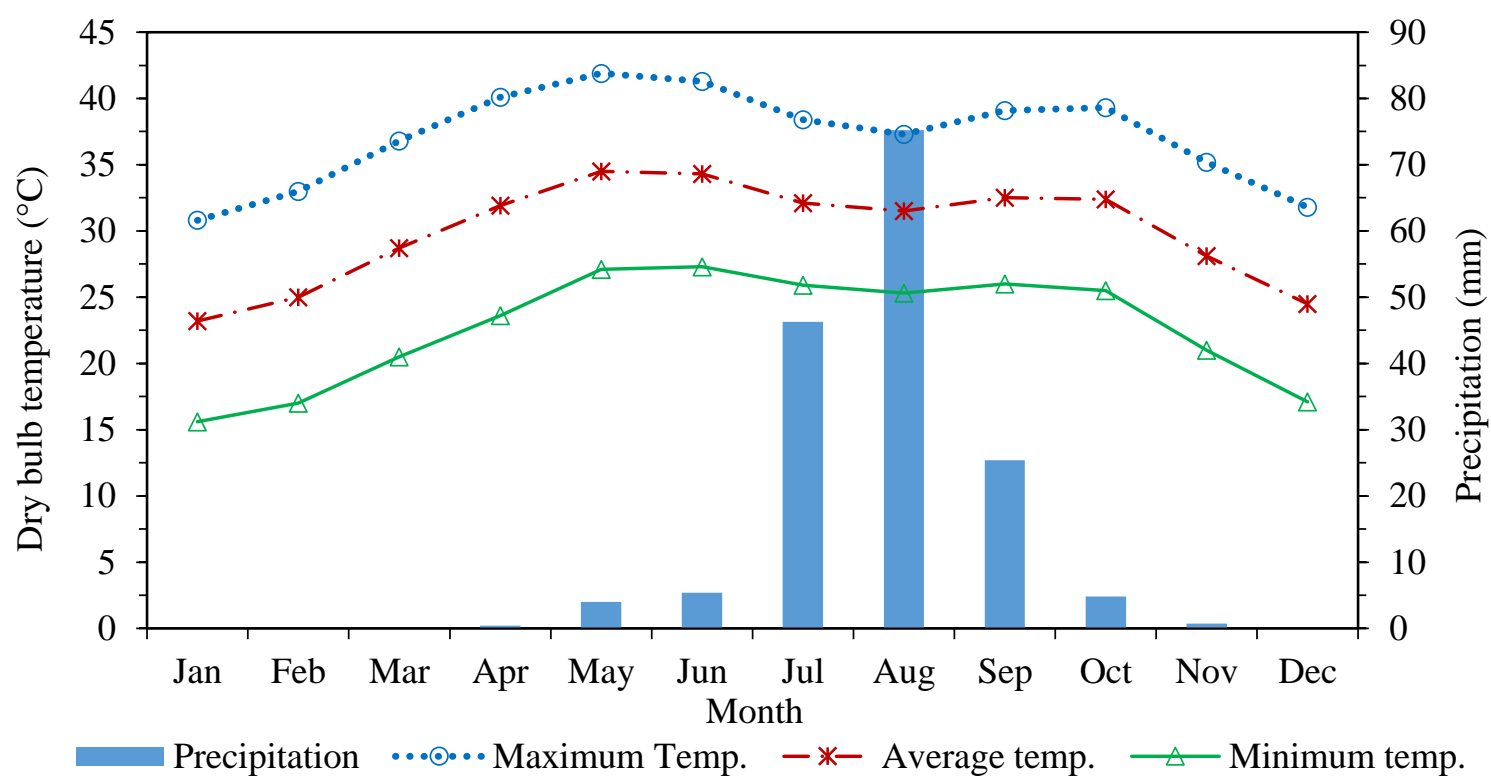

Figure 3: Monthly dry-bulb temperatures and precipitation rates for the site of Khartoum [46]. 


\subsection{Experiment setup}

The experiments have been carried out in a laboratory environment where an environmental chamber was used to simulate the climate conditions of the hot-arid regions. A schematic diagram and a photograph of the experimental setup are illustrated in Figure 4. When air temperature and humidity inside the chamber (1) reach the required values set using the chamber control panel (2), the axial fan (3) is used to blow the controlled air from the chamber at a given flow rate regulated by the fan speed controller (4) through the connected insulated duct. The air circulates through an insulated flexible duct (5) and a connected divergent with air guides (7) to the main duct which contains the PCM modules (9). The air extracts or adds heat to the PCM based on the operating mode (charging or discharging) before exiting the system through the outlet aperture (11) to the surrounding space. A data-taker (12) was used to acquire data from thermocouples (13) and records these for analysis.
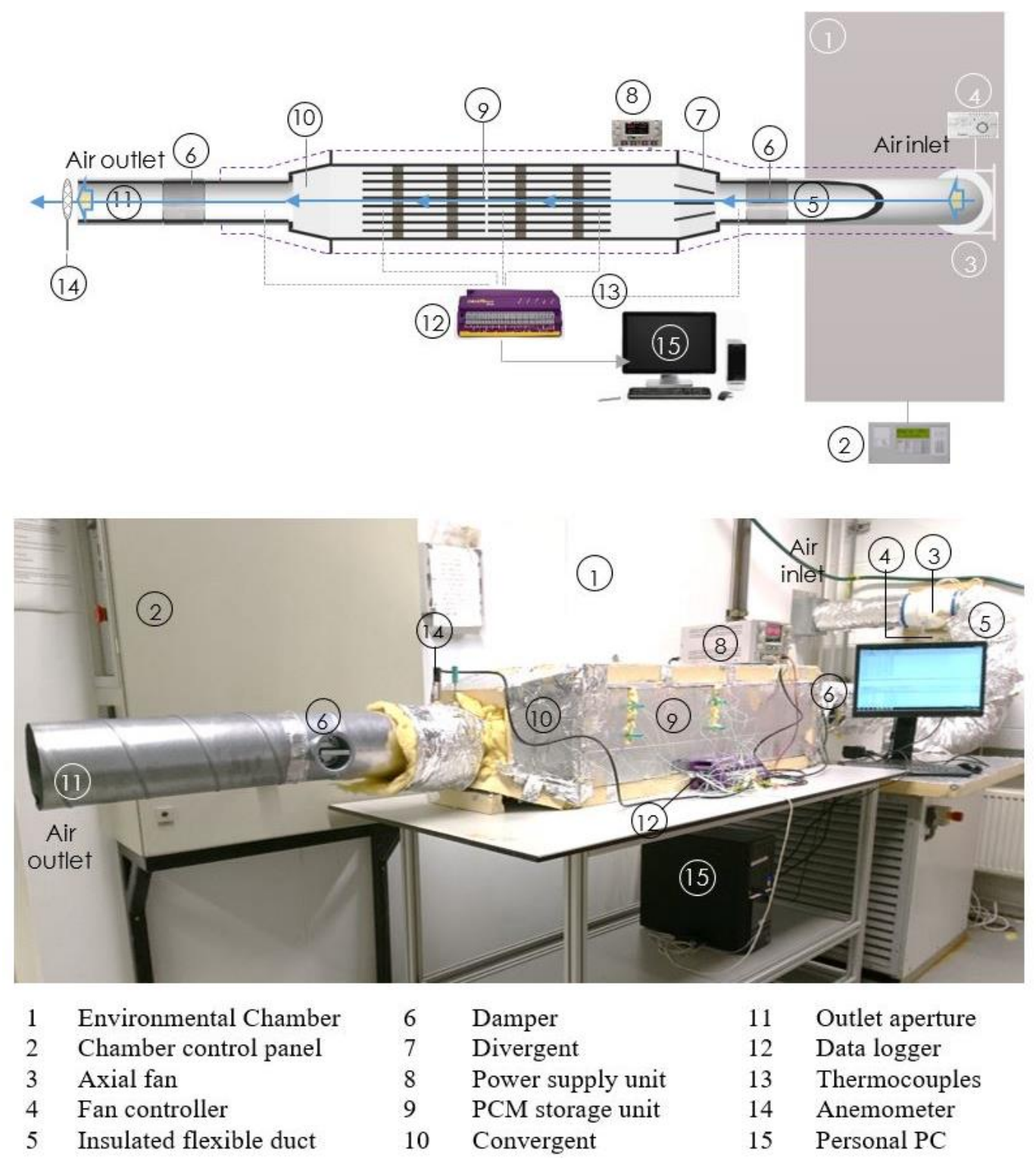

Figure 4: A schematic and a photograph of the experiment setup. 


\subsection{Instrumentation and measurements setup}

The measuring instruments used in the experiments included thermocouples for temperature measurement, anemometers for air flow, and a data taker for data acquisition and recording.

For temperature measurements, two types of thermocouples have been used; one to measure the temperature on the PCM container surface, and one for measuring the temperature of the air passing along the system. The temperature on the top surfaces of the PCM containers was measured using type $\mathrm{K}$ thermocouples with an accuracy of $\pm 0.4 \%$ and are suitable for temperatures measurement in the range $0^{\circ}$ to $+200^{\circ} \mathrm{C}$. As illustrated in Figure 5, eight thermocouples have been used; $1,2,3$, and 4 along the top surface of the $8^{\text {th }}$ (top) row modules and 5, 6,7, and 8 along the $4^{\text {th }}$ (middle) row modules. Moreover, the air temperature at various locations in the rig was measured using type $\mathrm{K}$ thermocouples of a stick probe with an accuracy of $\pm 0.4 \%$, and are suitable for temperatures measurement in the range $0^{\circ}$ to $+1100^{\circ} \mathrm{C}$. As shown in Figure 5, seven thermocouples have been used for air temperature measurement; two at the inlet (9) and the outlet (10); four distributed along the air channels (11 and 12 in the central air passage and 13 and 14 in the spacing between the top PCM modules and upper surface of the main duct); and number 15 installed out of the TES unit to measure the surrounding air temperature.

For air flow measurements, a handheld digital van anemometer measuring air velocities in the range $0.25-30 \mathrm{~m} / \mathrm{s}$ with an accuracy of $\pm 1 \%$ has been used at the duct outlet.

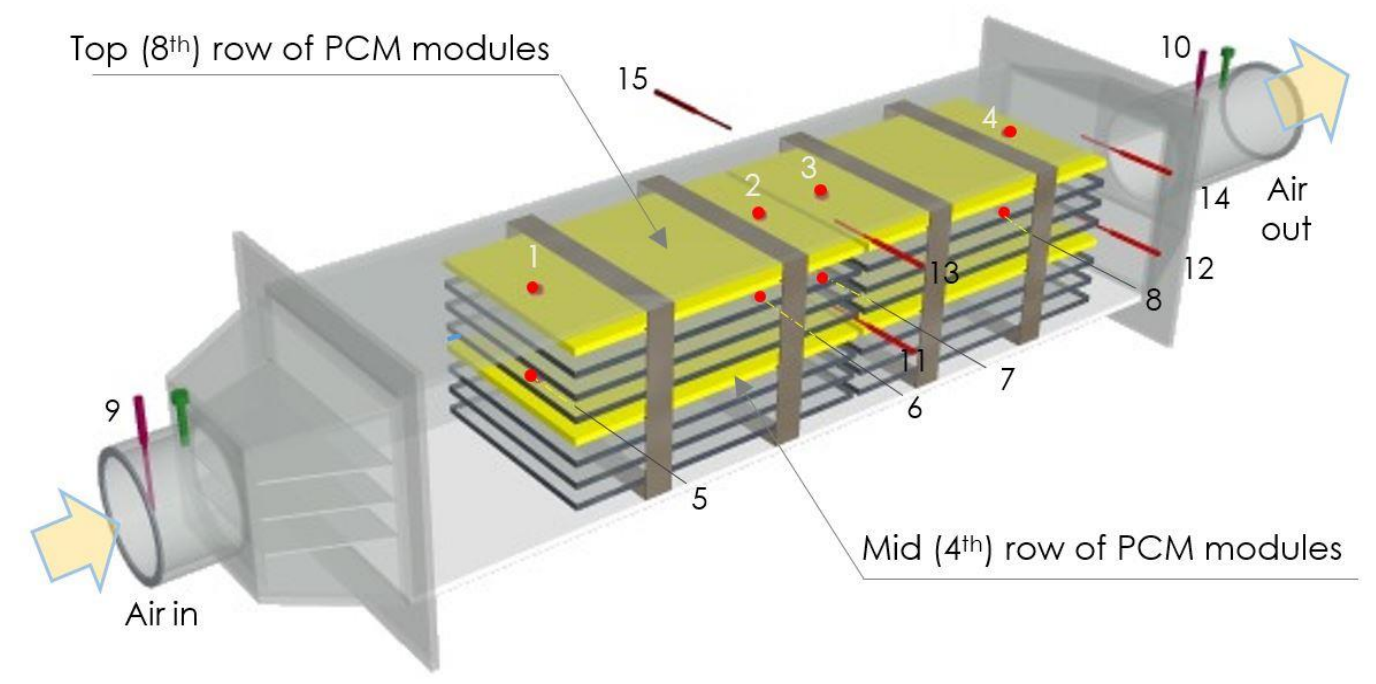
PCM top1
4 PCM_top4
7 PCM_mid3
10 Air outlet
13 Air_up1
PCM_top2
5 PCM mid1
8 PCM_mid4
11 Air cent 1
14 Air_up2
3 PCM top3
6 PCM_mid2
9 Air inlet
12 Air cent2
15 Air surrounding

Figure 5: A drawing showing the positions of thermocouples and pressure sensors. 
The uncertainty $\left(U_{\mathrm{x}}\right)$ of the measured parameters in the experiment was estimated utilising the method proposed by Moffat [47] based on the sensitivity of the measuring instruments $\left(\Delta x_{1}, \Delta x_{2}, \ldots \Delta x_{n}\right)$ and the minimum value of each independent variable considered $\left(x_{1}, x_{2}, \ldots x_{\mathrm{n}}\right)$ by equation $(1)$;

$$
U_{\mathrm{x}}=\sqrt{\left(\frac{\Delta x_{1}}{x_{1}}\right)^{2}+\left(\frac{\Delta x_{2}}{x_{2}}\right)^{2}+\cdots+\left(\frac{\Delta x_{\mathrm{n}}}{x_{\mathrm{n}}}\right)^{2}} \times 100 \%
$$

For the present experiments, the uncertainty can be attributed to the inaccuracy of temperature, air velocity, and PCM mass measurements, which has been estimated at $\pm 0.4 \%, \pm 1 \%$, and $\pm 0.32 \%$, respectively. Based on equation (1), the overall uncertainty of the experiment was estimated at $\pm 1.12 \%$.

\subsection{Experiment procedure}

In the current experiments, a range of inlet air temperatures and air flow rates have been investigated for both charging and discharging phases. Each test was performed considering a steady inlet temperature and air flow rate throughout the entire test period.

In the charging experiments, the PCM was initially fully melted at a temperature nearly $34{ }^{\circ} \mathrm{C}$, higher than its liquidus point by around $5 \mathrm{~K}$. Air temperature inside the chamber was set to a constant value lower than the PCM solidus point, and air humidity was set constant at $25 \%$. The selected air temperature and humidity were based on the ambient conditions observed during nights of summer and transitional months in Khartoum city, a hot-arid region (Figure 3). The rig was tested at three inlet air temperatures 21,23 , and $25{ }^{\circ} \mathrm{C}$ and three air volume flow rates 30,50 , and $70 \mathrm{~L} / \mathrm{s}$. When the fan is operated, the PCM releases its heat to the passing cold air from the chamber causing a gradual solidification of the PCM and accordingly increasing of the outlet air temperature with the progression of time. The system performance during the charging phase was assessed based on the time required to achieve a complete PCM solidification.

In the discharging experiments, the PCM was initially fully solidified at a temperature approximately $22{ }^{\circ} \mathrm{C}$, lower than its solidus point by $5 \mathrm{~K}$. Air temperature inside the chamber is higher than the PCM liquidus point, and air humidity was kept unchanged at $25 \%$ reflecting daytime ambient humidity typical of the hot-dry climate of Khartoum. Three inlet air temperatures 32,36 , and $40{ }^{\circ} \mathrm{C}$ and three air flow rates 7,16 , and $25 \mathrm{~L} / \mathrm{s}$ were considered. When the fan is operated, the PCM absorbs heat from the passing air leading to a gradual melting of the PCM. The system performance during the discharging phase was evaluated based on the melting time and the period in which the system is able to provide thermal comfort in buildings in hot-arid climates. It should be stressed that the comfort period has been estimated based on the assumption that the outlet air temperature from the system corresponds or very close to the room temperature, since the utilised ventilation rates were within the standard ventilation rates recommended [48]. 


\subsection{Assessment of PCM charging and discharging process}

The thermal performance of the PCM-air heat exchanger has been assessed experimentally using the thermal energy absorbed/released by the PCM during the charging/discharging processes.

Using heat balance analysis, the heat absorbed/released by the PCM ( $\left.Q_{\mathrm{PCM}}\right)$, and the heat gained/given up by the flowing air $\left(\Delta Q_{\mathrm{air}}=Q_{\mathrm{air}, \mathrm{in}}-Q_{\mathrm{air}, \mathrm{out}}\right)$ and the surrounding environment $\left(Q_{\text {exch }}\right)$ can be expressed as follows;

$$
Q_{\mathrm{PCM}}=\Delta Q_{\mathrm{air}}-Q_{\mathrm{exch}}
$$

The heat exchange rate of the air $\left(\Delta Q_{\text {air }}\right)$ at a time-step $i$ can be estimated knowing the temperature difference between the inlet air $\left(T_{\text {air,in }}\right)$ and the outlet air $\left(T_{\text {air,out }}\right)$ through the duct, the air mass flow rate $\left(\dot{m}_{\text {air }}\right)$, and the specific heat capacity of air $\left(C p_{\text {air }}\right)$ using the following equation;

$$
\Delta Q_{\text {air }}=\int_{t=0}^{i} \dot{m}_{\text {air }} C p_{\text {air }}\left(T_{\text {air,out }}-T_{\text {air,in }}\right) d t
$$

The heat exchange rate between the TES unit and the surrounding environment $\left(Q_{\text {exch }}\right)$ is estimated by the following relation;

$$
Q_{\text {exch }}=U A\left(T_{\text {surround }}-T_{\mathrm{TES}}\right)
$$

where; $A$ is the surface area of the TES enclosure, $T_{\text {surround }}$ is the surrounding air temperature measured around the test rig in the lab space, $T_{\mathrm{TES}}$ is the temperature of the TES unit assumed as an average temperature of the inlet and outlet air, and $U$ is the overall heat transfer coefficient estimated using equation (5);

$$
U=\frac{1}{\left(\frac{1}{h_{\mathrm{si}}}\right)+\left(\frac{\lambda_{\text {wall }}}{d_{\text {wall }}}+\frac{\lambda_{\text {ins }}}{d_{\text {ins }}}\right)+\left(\frac{1}{h_{\mathrm{so}}}\right)}
$$

where; $h_{\mathrm{si}}$ and $h_{\text {so }}$ are convective heat transfer coefficients at the inside and outside surfaces of the TES unit, $\lambda_{\text {wall }}$ and $d_{\text {wall }}$ are thermal conductivity and thickness of the duct wall material, $\lambda_{i n s}$ and $d_{i n s}$ are thermal conductivity and thickness of the insulation used around the TES unit, respectively. 


\section{Results and discussion}

\subsection{PCM charging performance}

This section analyses and discusses the results of the PCM charging process for free cooling of buildings. It describes the charging process and assesses the impact of inlet operating conditions, air channels height, and PCM supercooling on the TES system performance.

During the charging mode, the cold air was drawn from the environmental chamber with constant temperature and flow rate over the PCM modules via a fan connected between them. The flowing air allowed heat removal from the liquid PCM which changed its state gradually to solid. The charging tests were carried out until the complete PCM solidification is achieved. The occurrence of full PCM solidification was determined at a time corresponding to the flexure point at which the outlet air temperature began to stabilise at a level equal or close to that of inlet air temperature. The measured PCM and air temperatures during full charging process are discussed for a case under the following conditions: a $10 \mathrm{~mm}$ distance between PCM modules; a steady inlet air temperature $23{ }^{\circ} \mathrm{C}$; a constant air flow rate of $70 \mathrm{~L} / \mathrm{s}$; and an initial temperature of the entire system $34{ }^{\circ} \mathrm{C}$.

\subsubsection{Charging process}

Figure 6 shows the variation in the measured temperatures during charging process along the PCM modules as detailed in Figure 5. PCM_mid1 to PCM_mid4 are the four points located on the top surface of the $4^{\text {th }}$ (middle) row modules, whereas PCM_top1 to PCM_top4 are those at similar positions along the $8^{\text {th }}$ (top) row modules. It is clear that the large temperature variation at the beginning of the charging operation allowed a high rate of heat transfer between the PCM and the HTF. This sensible cooling process takes place quickly so that the PCM temperature dropped steeply reaching its liquidus point in less than 25 minutes for the tested case. The PCM temperature continued decreasing beyond its liquidus point indicating a supercooling of about $1.0 \mathrm{~K}$ for a maximum duration of 20 minutes without any phase change. Then, the temperature rose up again to the liquidus point, at which the PCM commenced the solidification process showing a gradual temperature drop with the progression of time until the full solidification has achieved. The continuation of the cold air flow through the TES device afterwards triggered a sensible heat removal from the PCM until the system reached the steady state, whereby the outlet air temperature was almost equal to the inlet air temperature.

There was a variation in the time period and the rate of solidification for the different PCM modules based on their relative locations. The solidification periods of the middle row modules PCM_mid1 to PCM_mid4 were 2.6, 3.5, 4.1, and 4.8 hours, respectively (Figure 6a), while the solidification periods along the top row modules PCM_top1 to PCM_top4 were 2.7, 3.7, 4.4, and 5.1 hours, respectively (Figure 6b). These results denote that the solidification occurs faster in the front modules and prolongs in the later modules, owing to the air temperature gradient along the duct. On the other hand, when comparing temperatures of the middle row modules in Figure 6a with their counterparts at the top in Figure 6b, it could be observed that PCMs in the middle of the duct solidified faster than those at the top. The variation in solidification time was small for the modules adjacent to the inlet (5 minutes between PCM_mid1 and PCM_top1), and it increased progressively with the distance augment towards the outlet (20 
minutes between PCM_mid4 and PCM_top4). This variation is attributable to the higher heat transfer rate at the middle side of the duct where air velocity is relatively higher than at the upper and lower air channels. This indicates the importance of geometrical design to allow uniform and constant air flow through the PCM-air heat exchanger.
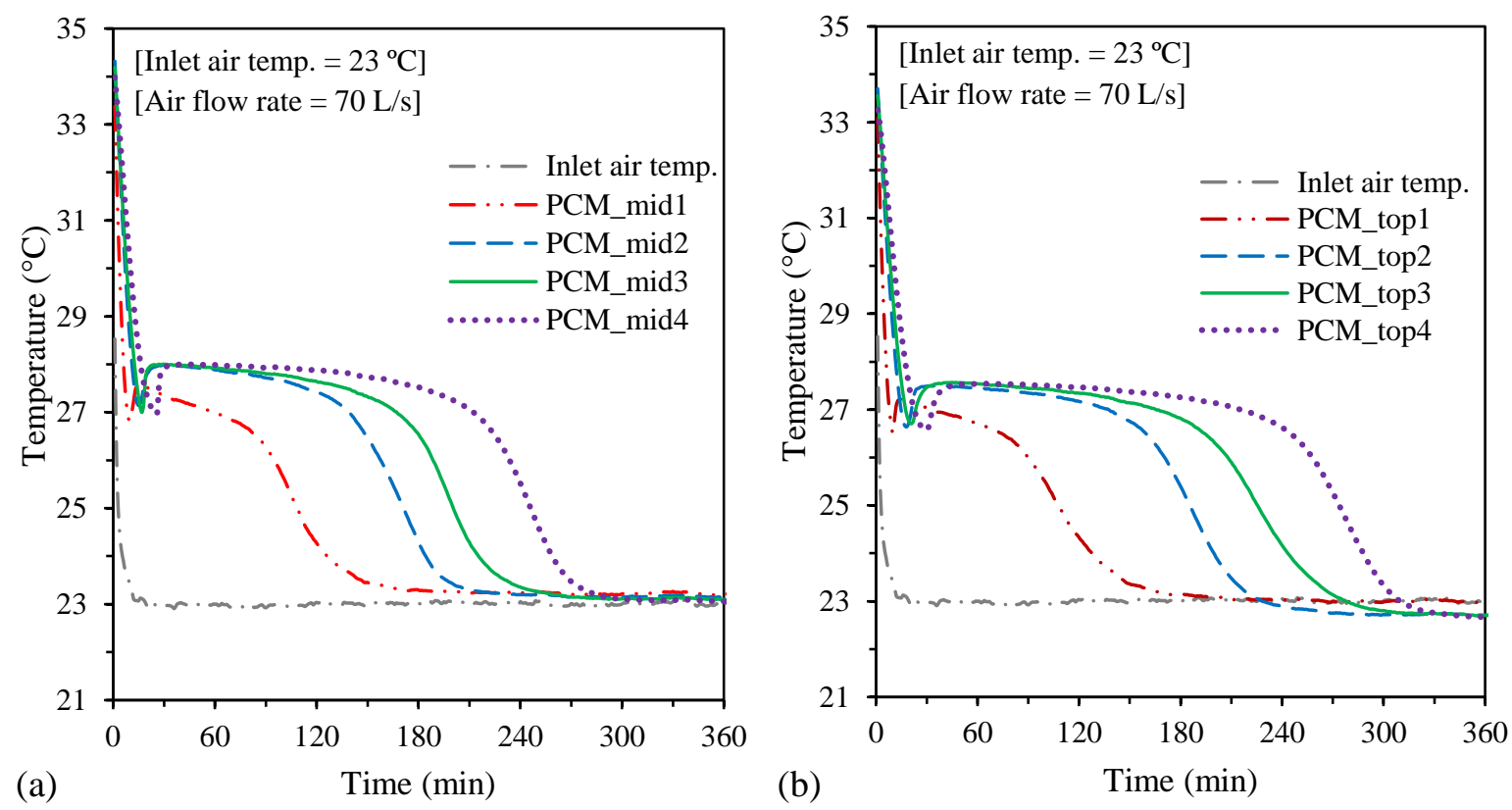

Figure 6: Variation of the PCM modules temperatures during the charging process at four locations along (a) the 4th-row modules "middle" (b) the 8th-row modules "top".

Figure 7 shows the variation of the measured air temperatures over the charging phase at various locations in the test rig. It is noticeable that the inlet air reached the target temperature of $23{ }^{\circ} \mathrm{C}$ in around 10 minutes and remained stable until the end of the charging period. Air temperature in the mid-region of the duct (Air_cent1 and Air_up1) was lower than that in the end region (Air_cent2 and Air_up2, respectively). This was due to a predicted drop in the heat removal factor from the PCM over the air duct as reflected in the air temperature gradient. Moreover, air temperatures at the central channels (Air_cent1 and Air_cent2) and in the upper channel (Air_up1 and Air_up2, respectively) followed a similar trend. However, the central channel air exhibited a slightly higher temperature profile by around $0.2 \mathrm{~K}$ during the phase change period due to the high heat transfer rate that usually attributed to the air velocity increase in the middle region of the duct compared to the top region. Afterwards, the situation reversed so that air temperature in the central channel dropped below that at the upper channel for the rest of the charging period, owing to the solidification of the PCM in the middle modules more than the top modules. Additionally, it is worth mentioning that the convergence between the inlet and the outlet air temperatures shown in Figure 7 after completion of the PCM charging denotes that the convective gain from surrounding was significantly low, i.e. the TES device was well-insulated. 


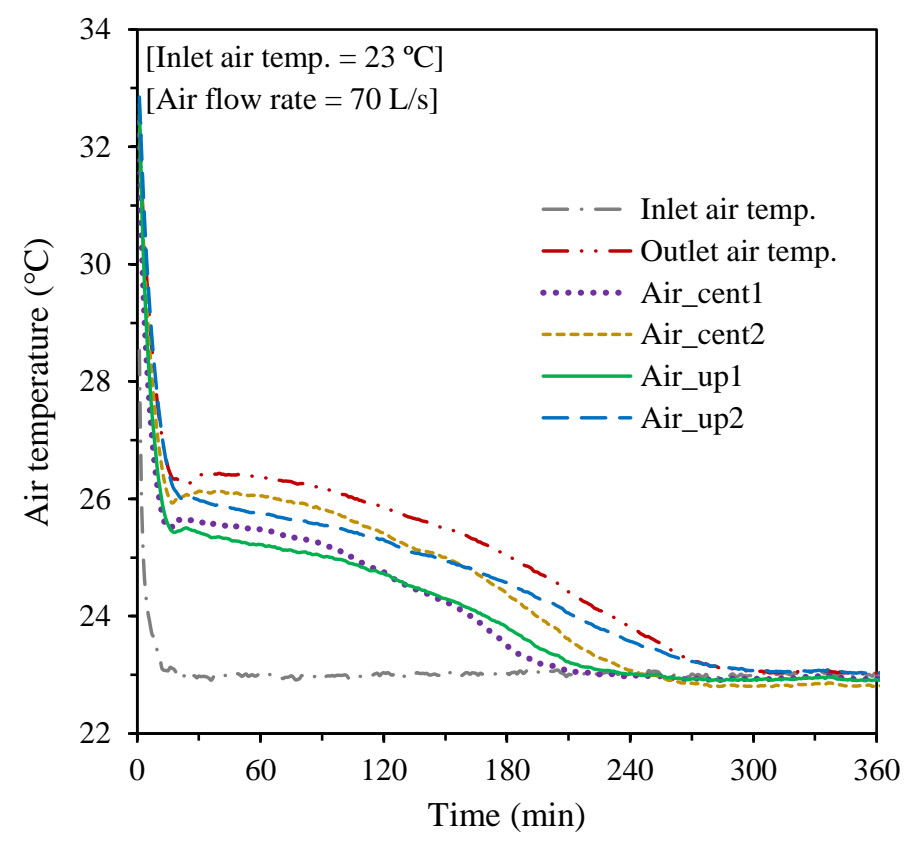

Figure 7: Air temperature variation in the test rig during the charging phase.

\subsubsection{Influence of inlet operating conditions}

The impact of both inlet air temperature and air flow rate on the thermal performance of the PCM-air heat exchanger during the charging process was discussed based on the tests conditions shown in Table 3. Moreover, the PCM solidification time was discussed under all combinations of the adopted charging air temperatures and flow rates.

Table 3: Inlet air conditions for the charging process.

\begin{tabular}{llll}
\hline & PCM initial temp. & Inlet air temp. & Air flow rate \\
\hline Inlet air temp. test & $34{ }^{\circ} \mathrm{C}$ & 21,23 , and $25{ }^{\circ} \mathrm{C}$ & $70 \mathrm{~L} / \mathrm{s}$ \\
Air flow rate test & $34{ }^{\circ} \mathrm{C}$ & $23{ }^{\circ} \mathrm{C}$ & 30,50, and $70 \mathrm{~L} / \mathrm{s}$ \\
\hline
\end{tabular}

The impact of inlet air temperature on the PCM charging is shown in Figure 8, which compares the outlet air temperatures and the cooling rate of the PCM for the three adopted inlet air temperatures, during the charging phase. It is evident that the higher the inlet air temperature, the lower the rate of heat removal from the PCM. Decreasing the inlet air temperature by $2 \mathrm{~K}$ from 23 to $21{ }^{\circ} \mathrm{C}$ reduced the solidification time by almost $25 \%$ from 4.8 to 3.6 hours, while increasing the inlet air temperature by $2 \mathrm{~K}$ from 23 to $25^{\circ} \mathrm{C}$ extended the solidification time to almost double ( 7.2 hours). These findings demonstrate that the charging performance is largely subject to the temperature difference between the inlet air and the PCM liquidus point, the larger the variation, the faster the solidification and vice versa. 

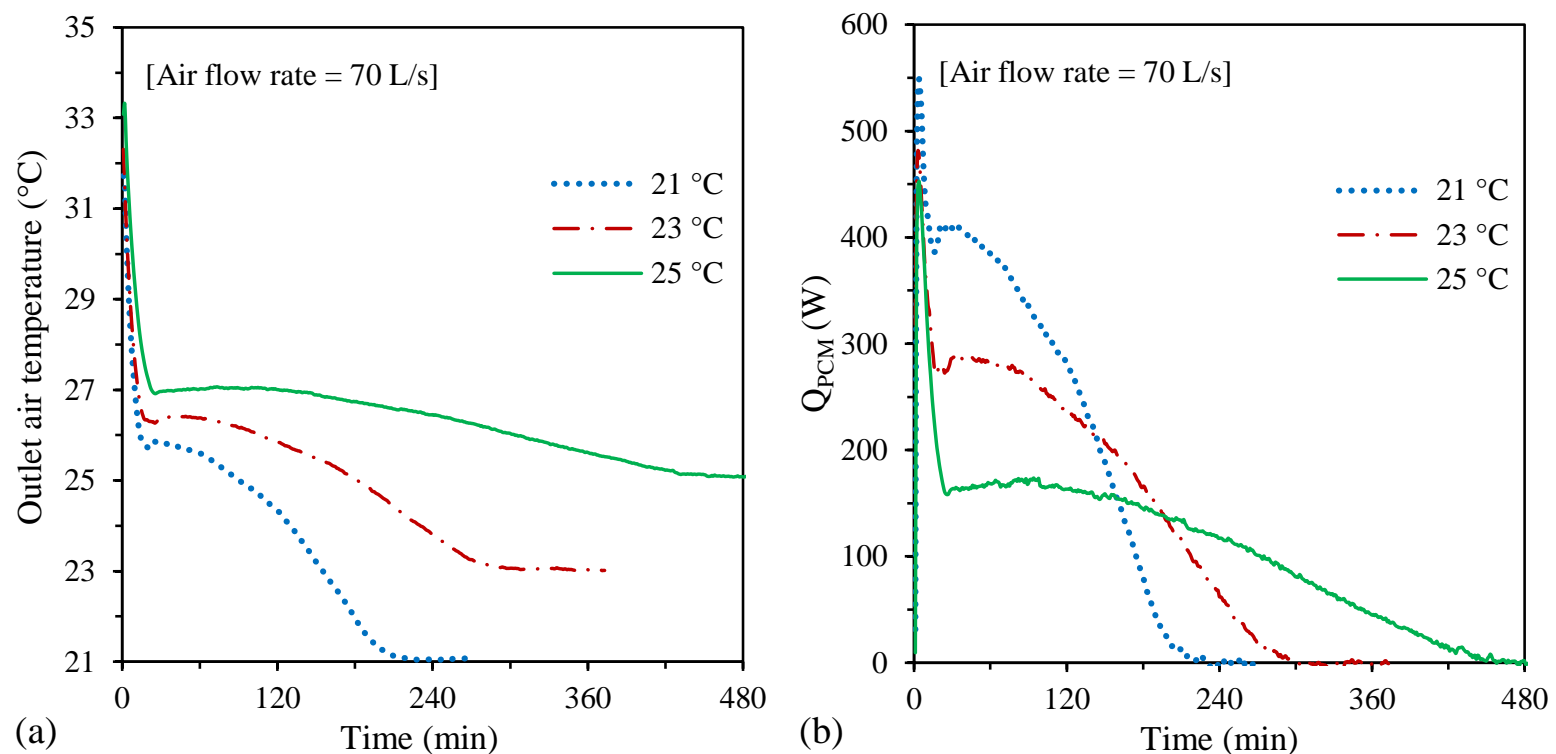

Figure 8: Impact of inlet air temperature on the PCM charging; variation in (a) the outlet air temperature, and (b) the PCM cooling rate.

The impact of air flow rate on the PCM charging is presented in Figure 9, which shows the variation of the outlet air temperatures and the PCM cooling rate over the charging period. It is evident that the higher the air flow rate, the higher the rate of cooling rate of the PCM during the phase change period, hence, the quicker the PCM solidification rate and vice versa. The rate of heat removal from the PCM was higher at the beginning of the charging process and declined gradually as the temperature difference between the PCM and the HTF decreased. Increasing the air flow rate by $40 \%$ from 50 to $70 \mathrm{~L} / \mathrm{s}$ reduced the solidification time by nearly $24 \%$ from 6.3 hours to 4.8 hours, whilst reducing the flow rate by a similar percentage from 50 to $30 \mathrm{~L} / \mathrm{s}$ increased the solidification time by $50 \%$ to about 9.4 hours. Thus, it is noted that the air flow rate has a significant influence on the PCM charging time, and therefore higher air flow rates are highly recommended to effectively exploit the available natural cooling energy and accelerate the solidification process.

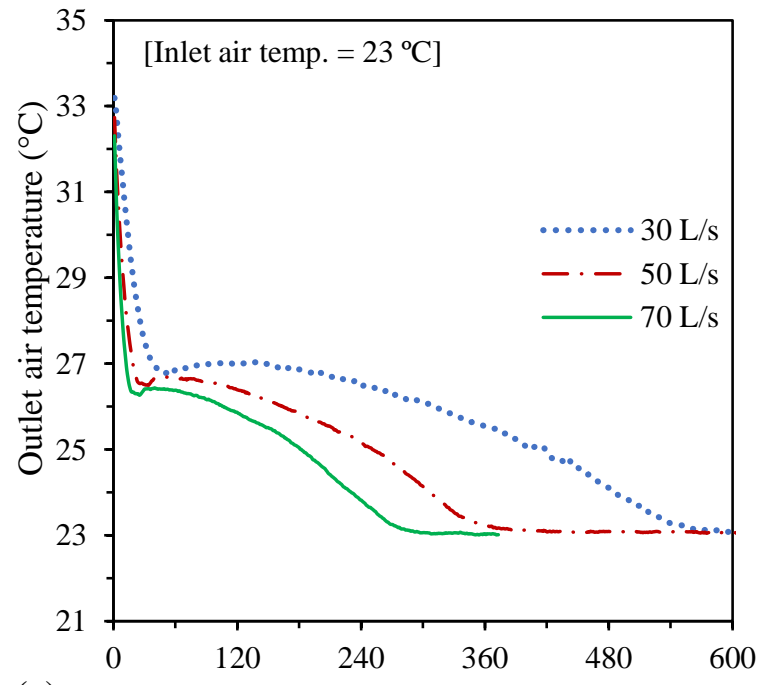

(a)

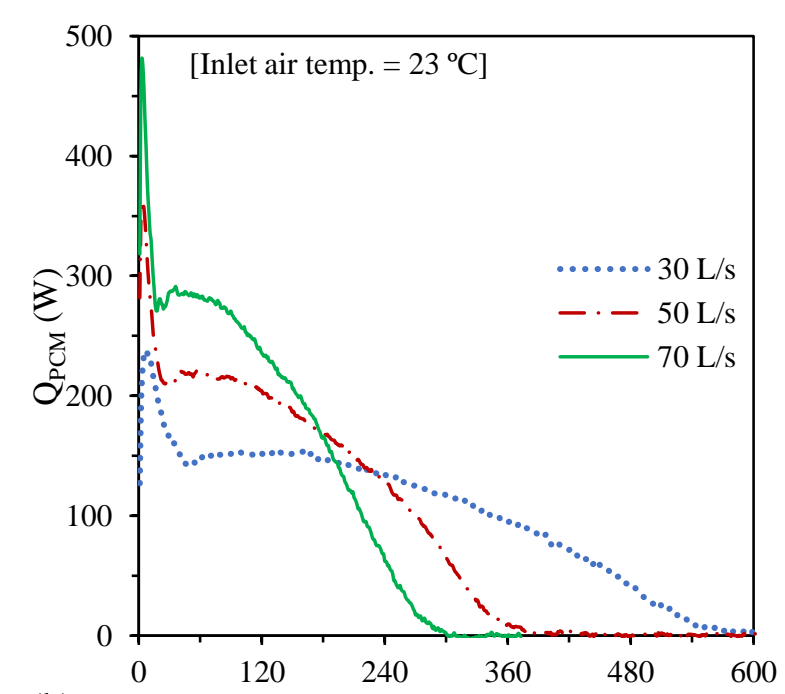

(b)

Time (min)

Figure 9: Impact of air flow rate on the PCM charging; variation in (a) the outlet air temperature, and (b) the PCM cooling rate. 
The combined influence of both inlet air temperature and air volume flow rate on PCM charging time is examined in order to find out the best time required for attaining a complete PCM solidification. As illustrated in Figure 10, each inlet air temperature has been tested under the three adopted air flow rates. It is observed that, at any air flow rate, an inlet air temperature rise from 21 to $23{ }^{\circ} \mathrm{C}$ increased the solidification time by around $33 \%$. An additional rise in temperature by $2 \mathrm{~K}$ to $25^{\circ} \mathrm{C}$ enhanced the solidification time by $50 \%$, which represents doubles the time compared to the lower charging temperature of $21{ }^{\circ} \mathrm{C}$. That means, the increase of solidification time with inlet air temperature rise is not linear. It illustrated a gradual rise at low inlet air temperature range, which changed to a sharp rise at the inlet air temperature range close to the PCM solidus point. On the other hand, for any charging air temperature, the solidification time alteration with air flow rate has a nonlinear relation. It illustrated a significant drop by about $33 \%$ at low air flow rates from 30 to $50 \mathrm{~L} / \mathrm{s}$ and a gradual drop by around $24 \%$ at high air flow rates from 50 to $70 \mathrm{~L} / \mathrm{s}$.

Additionally, observation of Figure 10 demonstrates that combining a high inlet air temperature with a high air flow rate in many cases may trigger a solidification time almost similar to one reached by a lower charging temperature at a lower air flow rate. For instance, the solidification periods obtained with inlet air temperature $25{ }^{\circ} \mathrm{C}$ at air flow rate $70 \mathrm{~L} / \mathrm{s}$ and with inlet air temperature $21^{\circ} \mathrm{C}$ at $30 \mathrm{~L} / \mathrm{s}$ were 7.2 hours and 7.1 hours, respectively, with a discrepancy less than $2 \%$ ( 8 minutes). Thus, the air flow rate should be carefully considered based on the charging ambient air temperature to harness the most out of free cooling in the required time using a low input power to the fan.

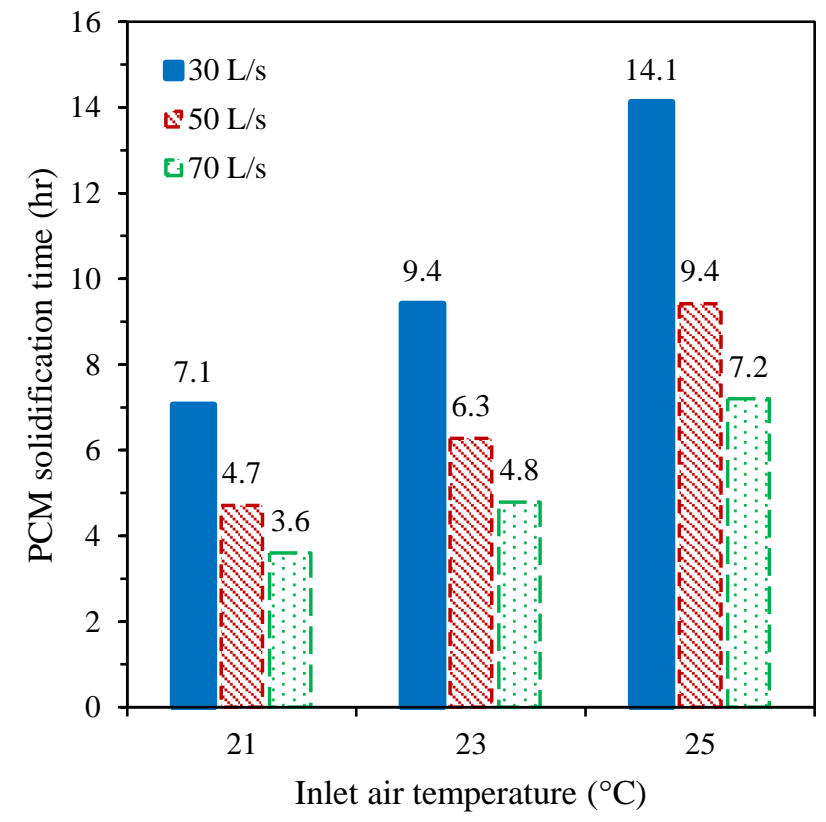

Figure 10: PCM solidification period under operating conditions of the charging process. 


\subsubsection{Influence of air channels height}

In order to maximise the amount of cooling energy accumulated in the PCM, the impact of the TES compactness was investigated. The number of PCM modules was kept constant, and only the distance between the modules was varied. Three cases were tested A, B, and C with air channels heights of 20,15 , and $10 \mathrm{~mm}$, respectively. The test was carried out under operating conditions shown in Table 3 above.

Figure 11 compares the outlet air temperature and the heat transfer rate for the three tested cases at the inlet air temperatures of $23{ }^{\circ} \mathrm{C}$ and the air flow rate of $70 \mathrm{~L} / \mathrm{s}$. It is noticed that the outlet air temperature in the case of the smaller channels height arrangement was higher during the initial half of the charging period and lower during the latter period than the larger channels height arrangement (Figure 11a). The TES system with a smaller channels height exhibited a higher cooling energy storage rate during the phase change period compared to that of larger channels height (Figure 11b). This is attributed to the enhanced heat transfer rate yielded by air velocity increase inside the narrow channels leading to a faster solidification time. Moreover, it is clear that a longer solidification time is required with larger air flow channels. At inlet air temperature $23{ }^{\circ} \mathrm{C}$ and air flow rate $70 \mathrm{~L} / \mathrm{s}$, the charging periods were 5.6, 5.2, and 4.8 hours for cases $\mathrm{A}, \mathrm{B}$, and $\mathrm{C}$, respectively, with the narrow channels achieving faster solidification.
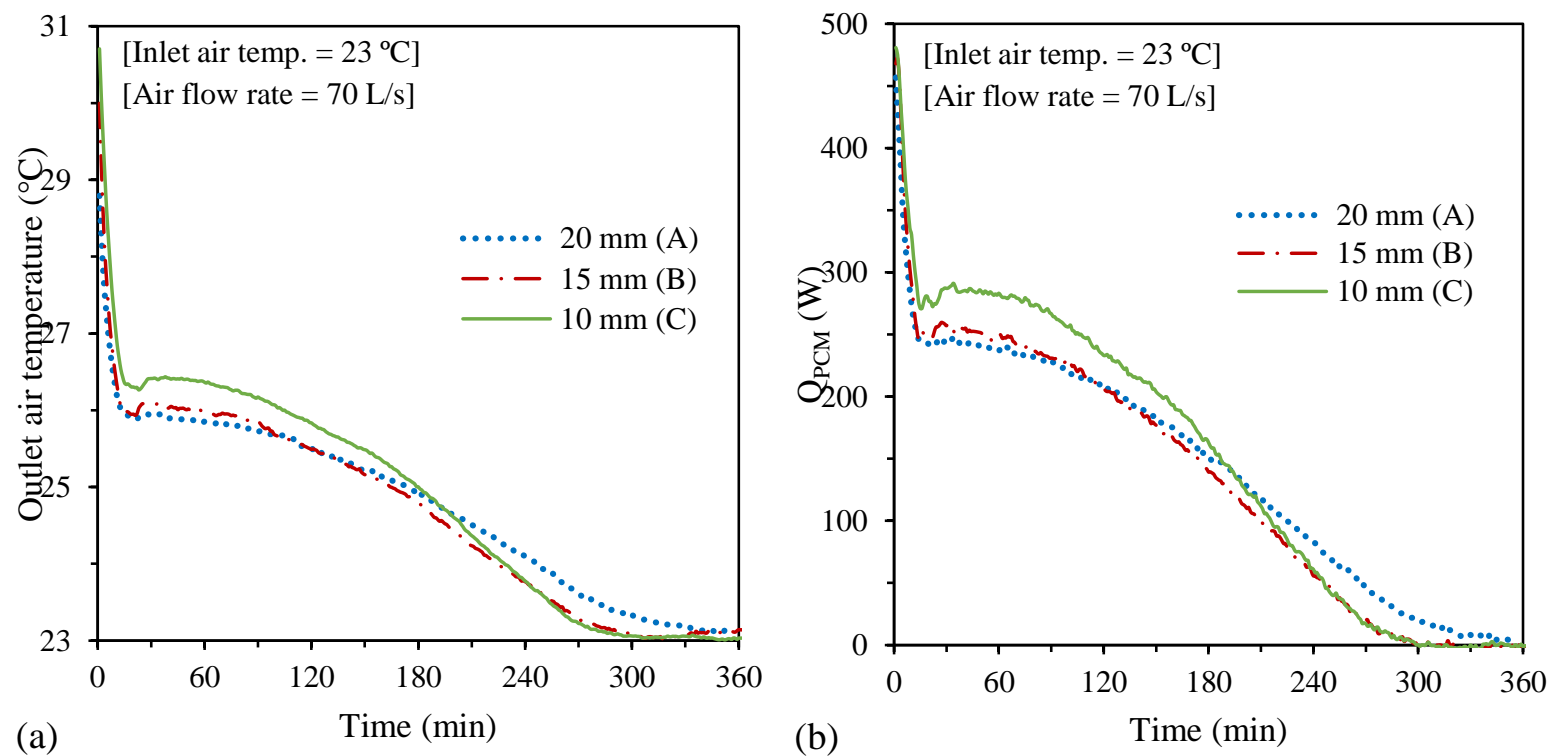

Figure 11: Impact of air channels height on the PCM charging; variation in (a) the outlet air temperature, and (b) the PCM cooling rate.

The required time for achieving a complete PCM solidification can be used to assess the compactness of the TES design by minimising or optimising the height of the air channel. The charging time for the three TES arrangements under the adopted operating conditions is presented in Figure 12. It can be clearly seen that the increase of PCM charging time with the air channels height increase is varied according to charging inlet air temperature. For the considered range of inlet temperatures $\left(32-40{ }^{\circ} \mathrm{C}\right)$, minimising the air channels height from 20 to $10 \mathrm{~mm}$ accelerated the melting time by $11-14 \%$, when the air flow rate was $70 \mathrm{~L} / \mathrm{s}$ (Figure 12a). On the other hand, the delay in PCM charging with the increase of air channels height is 
also varied depending on the air flow rate. However, the variations were generally small. For the considered range of air flow rates $(30-70 \mathrm{~L} / \mathrm{s})$, the reduction in PCM charging period was in the range 10-14\% when lessening the air channels height from 20 to $10 \mathrm{~mm}$, when the inlet air temperature was $23{ }^{\circ} \mathrm{C}$ (Figure $12 \mathrm{~b}$ ).
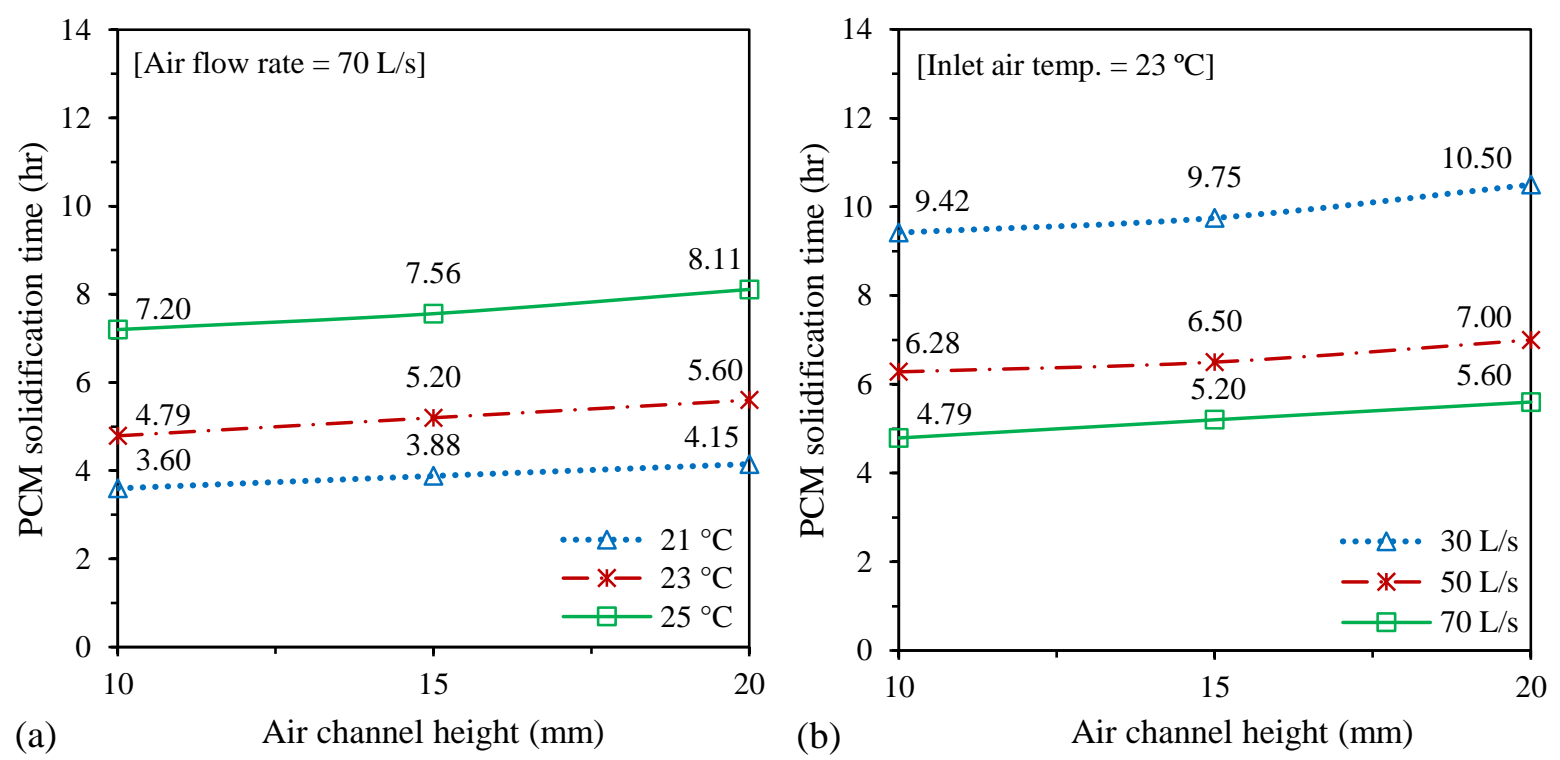

Figure 12: Sensitivity of PCM solidification time to the air channels height under various (a) inlet air temperatures, and (b) air flow rates.

In brief, narrow air flow channels are highly desirable for achieving quicker PCM solidification during the charging phase. The negative impact is that narrow channels may induce a high pressure drop and hence, higher fan power requirements. Overall, a compact PCM-air heat exchanger is more efficient during the charging process.

\subsubsection{Influence of PCM supercooling}

Supercooling of the liquid phase at the beginning of the charging process is one of the common drawbacks that limit the PCM usage for building cooling and heating owing to the associated heat transfer problem. The supercooling nearly occurred at a similar temperature drop in all PCM zones. However, its duration varies in accordance with the PCM cooling behaviour. The supercooling duration was shorter in the front modules and longer in the rear modules towards the outlet. This conclusion was deduced from Figure 6 that presents the measured temperatures at eight different PCM locations in the TES device.

To find out in what manner the supercooling is being affected by the operating conditions, the temperature-time relation was plotted for the PCM-mid3 during the initial 70 minutes of the charging process in Figure 13a for varied charging air temperatures, and in Figure 13b for varied air flow rates. It has been noticed that the PCM exhibited a steady supercooling of around $1 \mathrm{~K}$ in all conditions. The inlet air temperature has a small influence on the supercooling duration. The supercooling remains longer whenever the charging temperature is closer to the PCM transition temperature. In the present case, the supercooling durations observed were 7 , 9, and 16 minutes at inlet air temperatures 21,23 , and $25{ }^{\circ} \mathrm{C}$, respectively (Figure 13a). Moreover, PCM supercooling is also affected by the air flow rate. Boosting the air flow rate

R. Zeinelabdein, 2019 
decreased the supercooling period slightly at the high flow rates 50 and $70 \mathrm{~L} / \mathrm{s}$ taking between 7 and 10 minutes, respectively, and significantly at the low air flow rate of $30 \mathrm{~L} / \mathrm{s}$ when the supercooling time prolonged to around 30 minutes (Figure 13b).

In short, the supercooling observed under all tested operating conditions in the current charging experiments was relatively small and had no obvious impact on the outlet air temperature. To reduce the impact of supercooling, the temperature difference between the PCM and air should be sufficient and making use of high air flow rates. If the charging air temperature was higher than the supercooling temperature of the PCM $\left(27^{\circ} \mathrm{C}\right.$ in this case), the solidification would not be initiated.
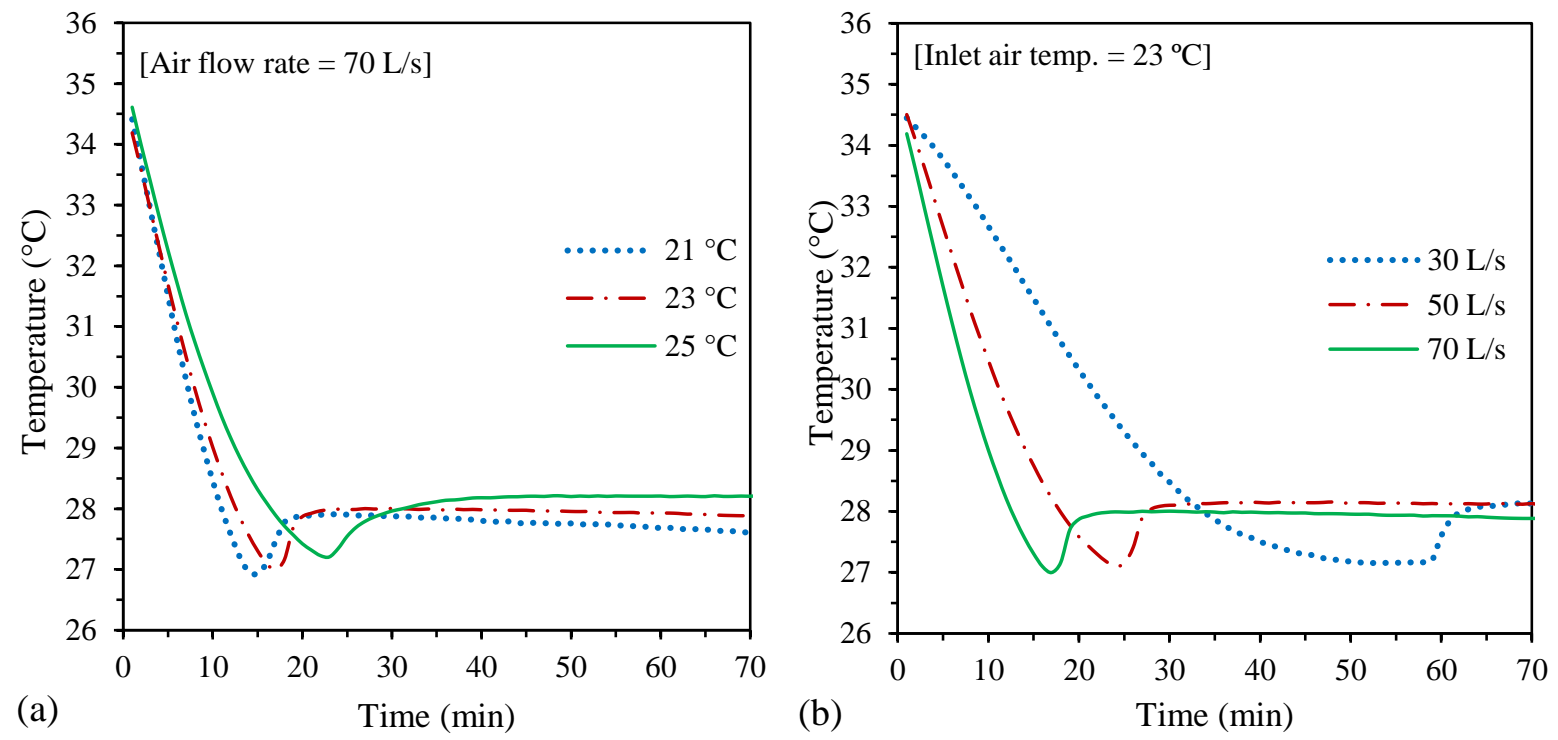

Figure 13: The supercooling at PCM-mid3 under the adopted (a) inlet air temperatures, and (b) air flow rates. 


\subsection{PCM discharging performance}

This section analyses and discusses the results of the discharging process of the TES system for free cooling of buildings. It explains the discharging process and assesses the impact of inlet operating conditions and air channels height on the PCM melting behaviour. The system performance was evaluated based on the time required to achieve a complete PCM melting. The period in which the system is able to provide thermal comfort in buildings in hot-arid climates was also assessed, based on the assumption that the outlet air temperature corresponds or very close to the room temperature. In the present study, the adopted thermal comfort zone was based on the previous studies conducted by Merghani [49] and Nicol and Humphreys [50], who pointed out that an indoor air temperature in the range $25-30{ }^{\circ} \mathrm{C}$ is acceptable for human thermal comfort during summer in hot-arid climates, based on the adaptive thermal comfort principles.

During the discharging mode, a fan was used to draw the hot air from the environmental chamber with a constant temperature and flow rate over the PCM modules. The flowing air added heat to the solid PCM which changed its state gradually to liquid. The discharging tests were carried out until the entire PCM turned into liquid. The melting time was determined at the time the outlet air temperature started to stabilise around the inlet air temperature. The discharging behaviour is discussed for a case under the conditions: a $10 \mathrm{~mm}$ distance between the PCM modules; a steady inlet air temperature $36^{\circ} \mathrm{C}$; a constant air flow rate $16 \mathrm{~L} / \mathrm{s}$; and an initial PCM temperature $22^{\circ} \mathrm{C}$.

\subsubsection{Discharging process}

Figure 14 presents the measured temperatures during the discharging process at eight PCM locations as shown in Figure 5. The PCM temperature increased sharply at the beginning of the discharging process due to the sensible heat absorption until reaching the solidus temperature of about $27^{\circ} \mathrm{C}$. Afterwards, the phase transition from solid to liquid was activated and the PCM temperature increased gradually with the time until attaining the liquidus temperature of about $29{ }^{\circ} \mathrm{C}$. After which phase, the PCM went through a sensible heating phase, where its temperature rose sharply until reaching the steady state conditions around the inlet air temperature. The melting periods varied based on the PCM locations. Along the middle row modules PCM_mid1 to PCM_mid4, the melting periods were 5.3, 6.5, 8.7, and 8.8 hours, respectively (Figure 14a), and for those along the top row modules PCM_top1 to PCM_top4 were 5.0, 5.8, 8.2, and 8.7 hours, respectively (Figure 14b). These results have revealed that the melting occurred quicker in the front modules and slower in the rear modules, as a result of gradual air temperature drop towards the outlet. Another observation is that the top PCM modules melted faster than those in the middle, contrary to what occurred in the charging process. That means the heat transfer rate was higher at the upper and lower regions of the duct compared to the middle region. The reason behind that was the damper placement by an angle of $110^{\circ}$ to obtain the required air flow rate of $16 \mathrm{~L} / \mathrm{s}$, which enhanced the air flow through the top and bottom channels. 

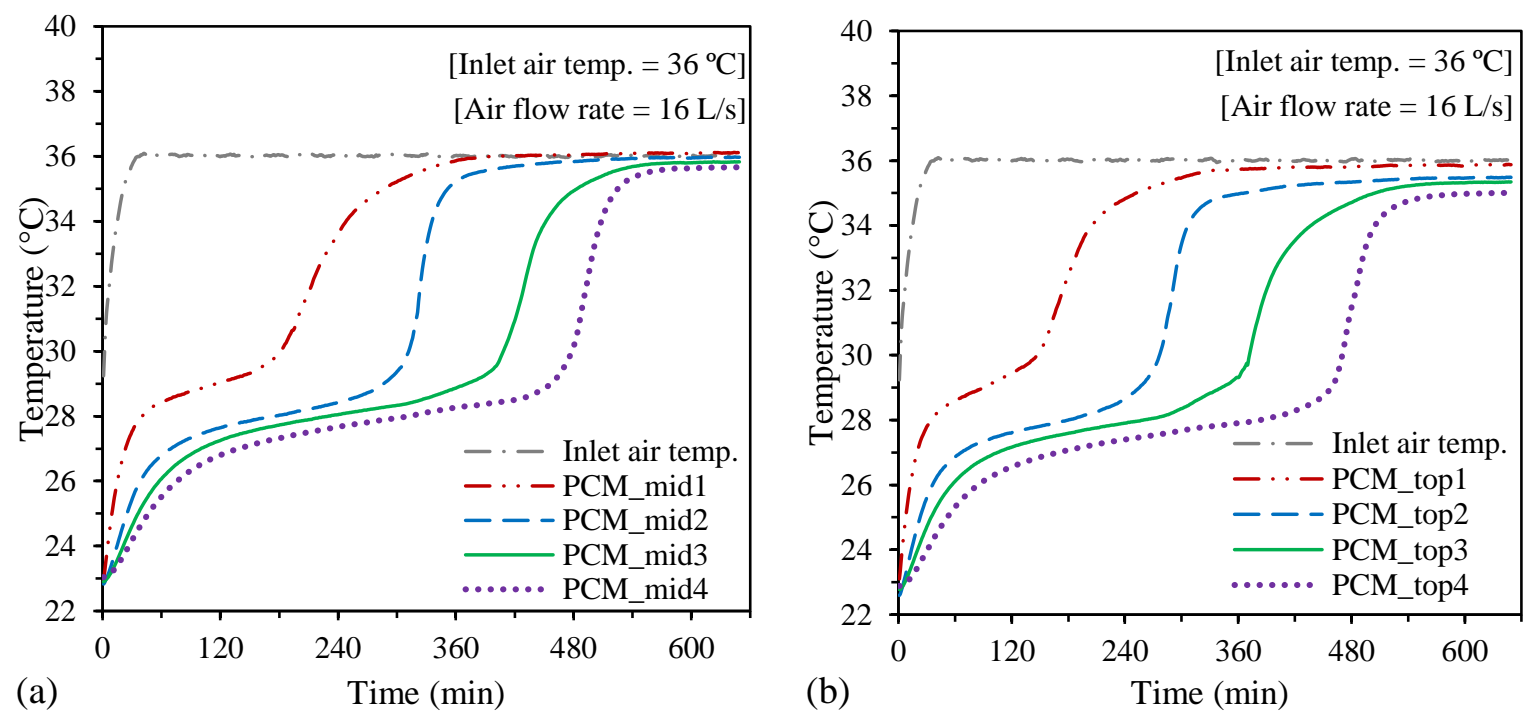

Figure 14: Variation of the PCM modules temperatures during the discharging process at four locations along (a) the 4th-row modules "middle" (b) the 8th-row modules "top".

Figure 15 exemplifies the variation of the measured air temperatures during the discharging process at various locations in the test rig. It is observed that the inlet air reached the targeted temperature of $36{ }^{\circ} \mathrm{C}$ in almost 25 minutes which remained constant until the end of the discharging period. The full melting of the PCM occurred after 8.9 hours and the outlet air temperature was within the comfort zone (below $30^{\circ} \mathrm{C}$ ) for around 6 hours. It can be clearly seen that air temperature in the middle of the duct (Air_cent1 and Air_up1) was higher than at the end (Air_cent2 and Air_up2), respectively, owing to the convective heat transfer rate drop along the air channels caused by the gradual drop in the temperature difference between the PCM and the HTF. Moreover, the upper channel positions (Air_up1 and Air_up2) demonstrated higher temperatures than their counterpart in the middle channel (Air_cent1 and Air_cent2), respectively, by around $0.9 \mathrm{~K}$ throughout the transition phase. This was due to the higher heat transfer rate as a result of the enhanced air velocity caused by the damper's positioning as previously stated.

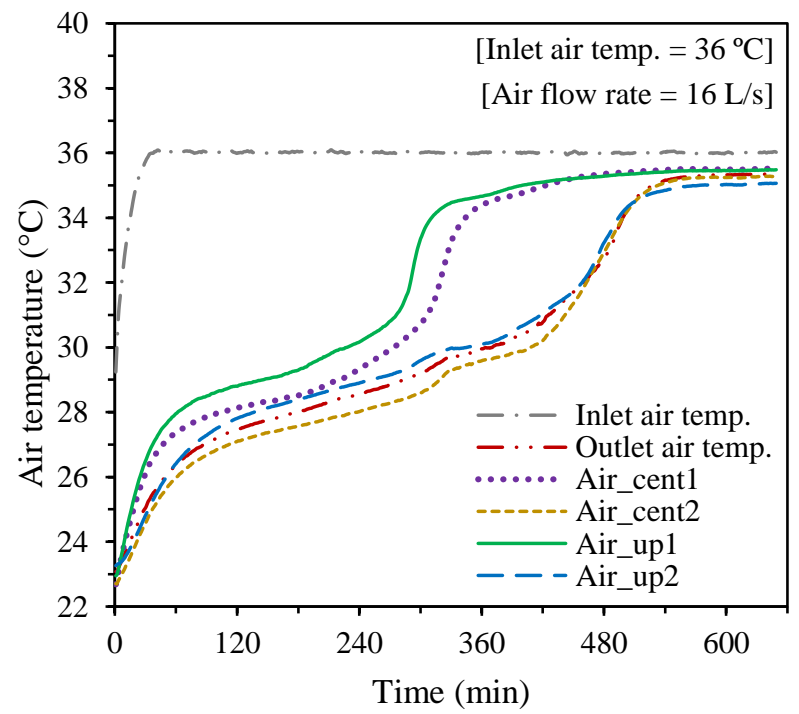

Figure 15: Air temperature variation in the test rig during the discharging phase.

R. Zeinelabdein, 2019 


\subsubsection{Influence of inlet operating conditions}

The impact of both inlet air temperature and air flow rate on the thermal performance of the TES system during the discharging process was discussed based on the inlet air conditions presented in Table 4. The PCM melting time and the period in which the outlet air temperature was within the comfort range were discussed under all combinations of the adopted air temperatures and flow rates.

Table 4: Inlet air conditions for the discharging process.

\begin{tabular}{llll}
\hline & PCM initial temp. & Inlet air temp. & Air flow rate \\
\hline Inlet air temp. test & $22{ }^{\circ} \mathrm{C}$ & 32,36 , and $40{ }^{\circ} \mathrm{C}$ & $16 \mathrm{~L} / \mathrm{s}$ \\
Air flow rate test & $22{ }^{\circ} \mathrm{C}$ & $36{ }^{\circ} \mathrm{C}$ & 7,16, and $25 \mathrm{~L} / \mathrm{s}$ \\
\hline
\end{tabular}

The impact of inlet air temperature on the PCM melting process is demonstrated in Figure 16, which compares the outlet air temperature and rate of heat absorbed by the PCM for the adopted inlet air temperatures. It is observed that the higher the inlet air temperature, the higher the rate of coolness extraction from the PCM, leading to a faster PCM melting and hence, a shorter thermal comfort period. Decreasing the inlet air temperature by $4 \mathrm{~K}$ from 36 to $32{ }^{\circ} \mathrm{C}$ boosted the melting time by around $80 \%$ from 8.8 to 15.8 hours and extended the thermal comfort period from 6.2 hours to 14.1 hours. While an increase in inlet air temperature by $4 \mathrm{~K}$ from 36 to $40{ }^{\circ} \mathrm{C}$ reduced the melting time by $26 \%$ to around 6.5 hours and reduced the comfort time by $40 \%$ to 3.7 hours. These findings indicate that the cooling discharging rate depends largely on the temperature difference between the inlet air and the PCM, and small differences are desirable to prolong the thermal comfort period.
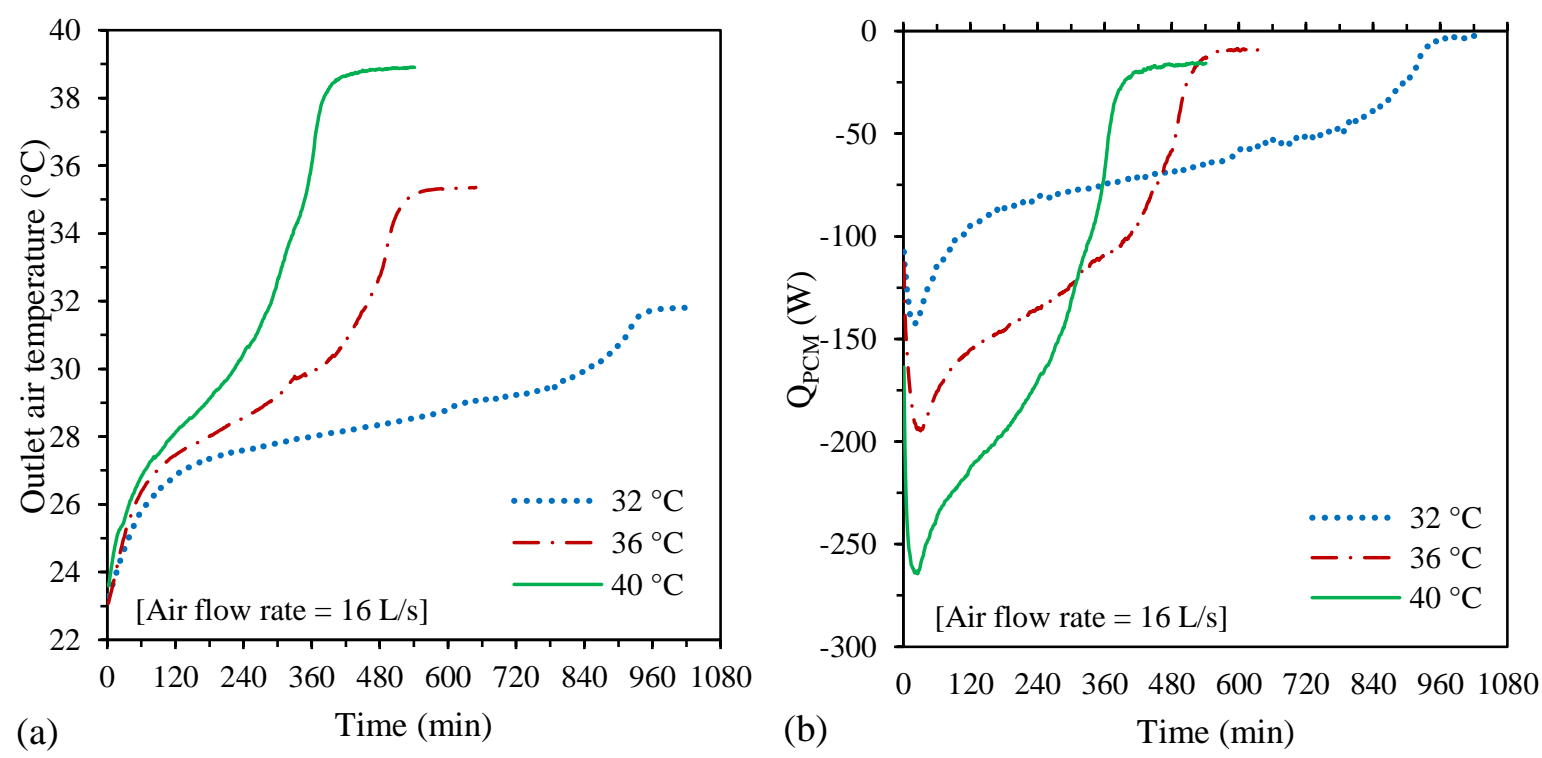

Figure 16: Impact of inlet air temperature on the PCM discharging; variation in (a) the outlet air temperature, and (b) the PCM heating rate. 
The impact of air flow rate on the PCM melting process is shown in Figure 17, which indicates the variation in the outlet air temperature and the rate of heat absorbed by the PCM for the adopted air flow rates. It is observed that the higher the air flow rate, the larger the heat absorption rate by the PCM during the transition phase, leading to a quicker PCM melting rate. The higher the air flow rate, the sharper the increase in the outlet air temperature, leading to a shorter comfort duration. Boosting the air flow rate by around $56 \%$ from $16 \mathrm{~L} / \mathrm{s}$ to $25 \mathrm{~L} / \mathrm{s}$ minimised the melting time by around $23 \%$ from 8.8 to 6.7 hours and the comfort period by around $47 \%$ from 6.2 to 3.3 hours. Whilst decreasing the flow rate by a similar ratio from 16 to $7 \mathrm{~L} / \mathrm{s}$ extended the melting time by $77 \%$ to about 15.5 hours and prolonged the comfort time to 13.5 hours. These results denote that lower air flow rates are required during the discharging operation to maintain longer comfort duration. However, the supplied air velocity should be within the limit provides comfort cooling.
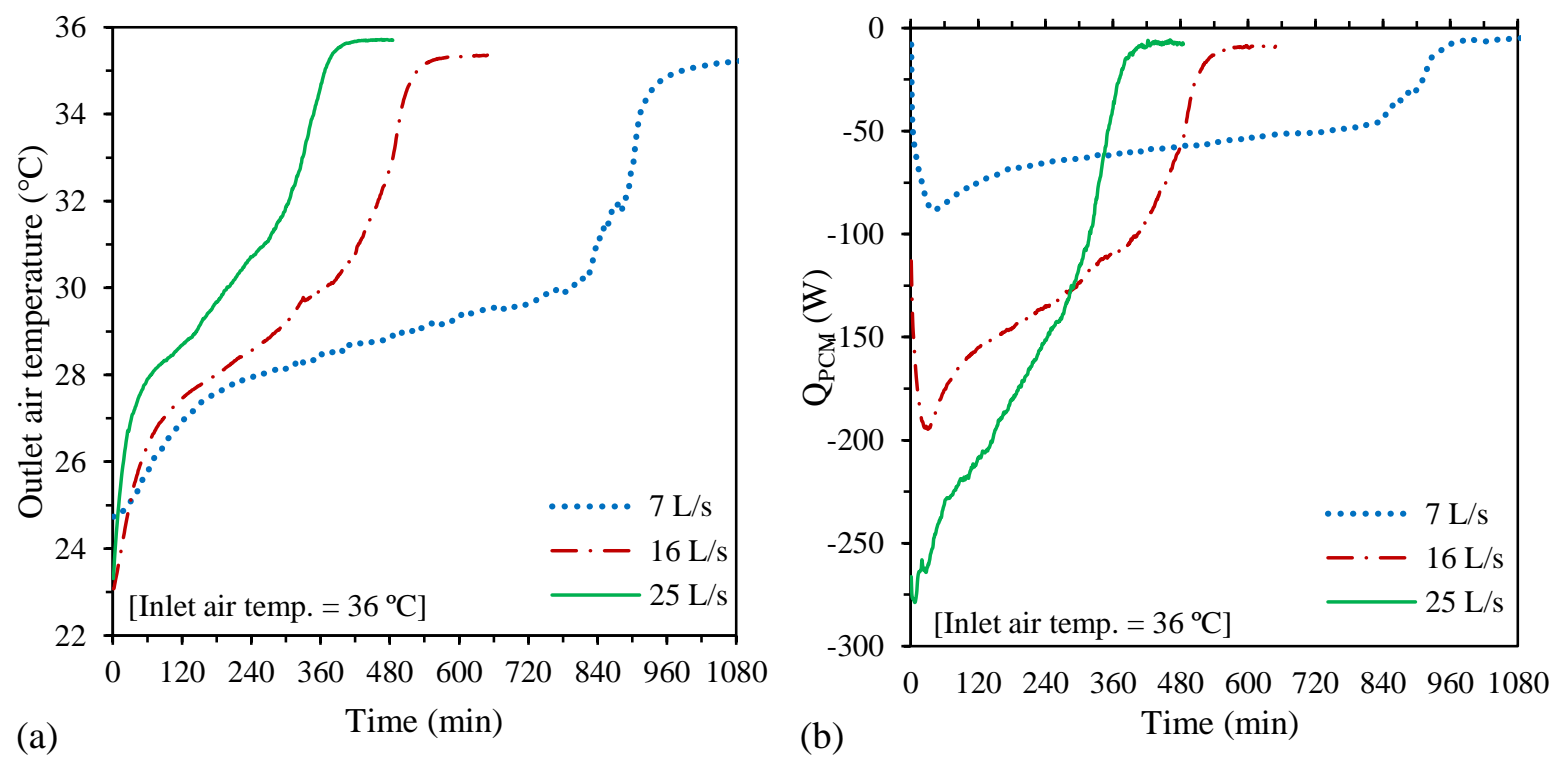

Figure 17: Impact of air flow rate on the PCM discharging; variation in (a) the outlet air temperature, and (b) the PCM heating rate.

The time required for attaining full PCM melting under all combination of the adopted inlet temperatures and air flow rates is presented in Figure 18a. The period in which the outlet air temperature is within the thermal comfort zone is shown in Figure 18b.

As shown in Figure 18a, for all flow rates, the melting time reduced by around $44 \%$ with the inlet air temperature rise from 32 to $36{ }^{\circ} \mathrm{C}$, and by $26 \%$ with the further rise from 36 to $38{ }^{\circ} \mathrm{C}$. On the other hand, the melting time decreased by $45 \%$ when the air flow rate enhanced from 7 to $16 \mathrm{~L} / \mathrm{s}$, and by $23 \%$ for a similar enhancement from 16 to $25 \mathrm{~L} / \mathrm{s}$. Therefore, regardless of the inlet air temperature, the melting time could be adjusted by adopting the right air flow rate.

During the discharging phase, the duration at which the outlet air temperature is within the thermal comfort zone is of main interest more than the time required for achieving complete PCM melting. The comfort period was determined based on the time the outlet air temperature was within the comfort range $\left(25-30{ }^{\circ} \mathrm{C}\right)$, assuming correspondence of the outlet air 
temperature with the room indoor temperature. In the case of outlet air temperature exceeded the comfort level, the operation of the free cooling system could assist in lowering the power consumption of the supportive conventional air conditioning system. Whilst switching off the system may allow commencing of the charging process with partially solidified PCM in the case of well-insulated units, which can be beneficial in the case of insufficient cooling availability during the night-time.

It is clear from Figure $18 \mathrm{~b}$ that the increase of inlet air temperature from 32 to $36{ }^{\circ} \mathrm{C}$ reduced the comfort period by $50-67 \%$, while an additional rise by $4 \mathrm{~K}$ to $40{ }^{\circ} \mathrm{C}$ has a lower reduction by $31-39 \%$, for the air flow rates $7-25 \mathrm{~L} / \mathrm{s}$, respectively. The reduction of comfort period with the air flow rise from 7 to $16 \mathrm{~L} / \mathrm{s}$ was in the range of $47-60 \%$, and with the air flow rise from 16 to $25 \mathrm{~L} / \mathrm{s}$ was $29-46 \%$, for the inlet temperature range $32-40{ }^{\circ} \mathrm{C}$, respectively.
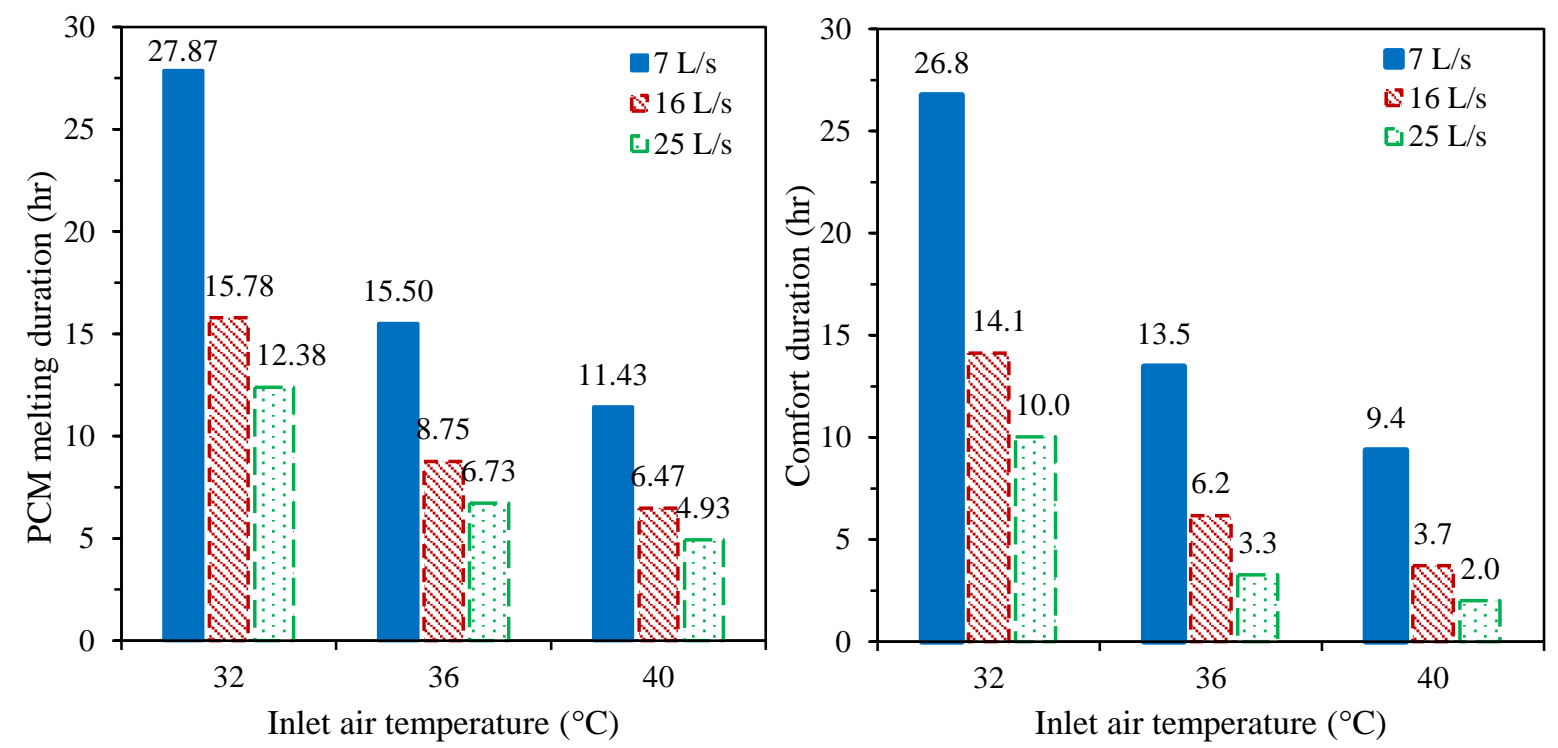

Figure 18: (a) PCM melting time, and (b) Comfort duration under operating conditions of the discharging process.

\subsubsection{Influence of air channels height}

Figure 19 compares the outlet air temperature and the PCM heating rate for the three tested cases, when the inlet air temperature was $36^{\circ} \mathrm{C}$ and the air flow rate was $16 \mathrm{~L} / \mathrm{s}$. It is observed that the smaller the air channels height the lower the outlet air temperature will be during the initial half of the discharging period. This was due to the higher heat transfer rate caused by the enhanced air velocity inside the narrower channels compared to the wider channels. This situation reversed after a certain period of time where the cooling extraction from the PCM was lower in the case of the smaller channels height, and hence, the outlet temperature increased more sharply resulting in a faster PCM melting. This occurred as the temperature difference between the PCM and the air gradually dropped with the time. 

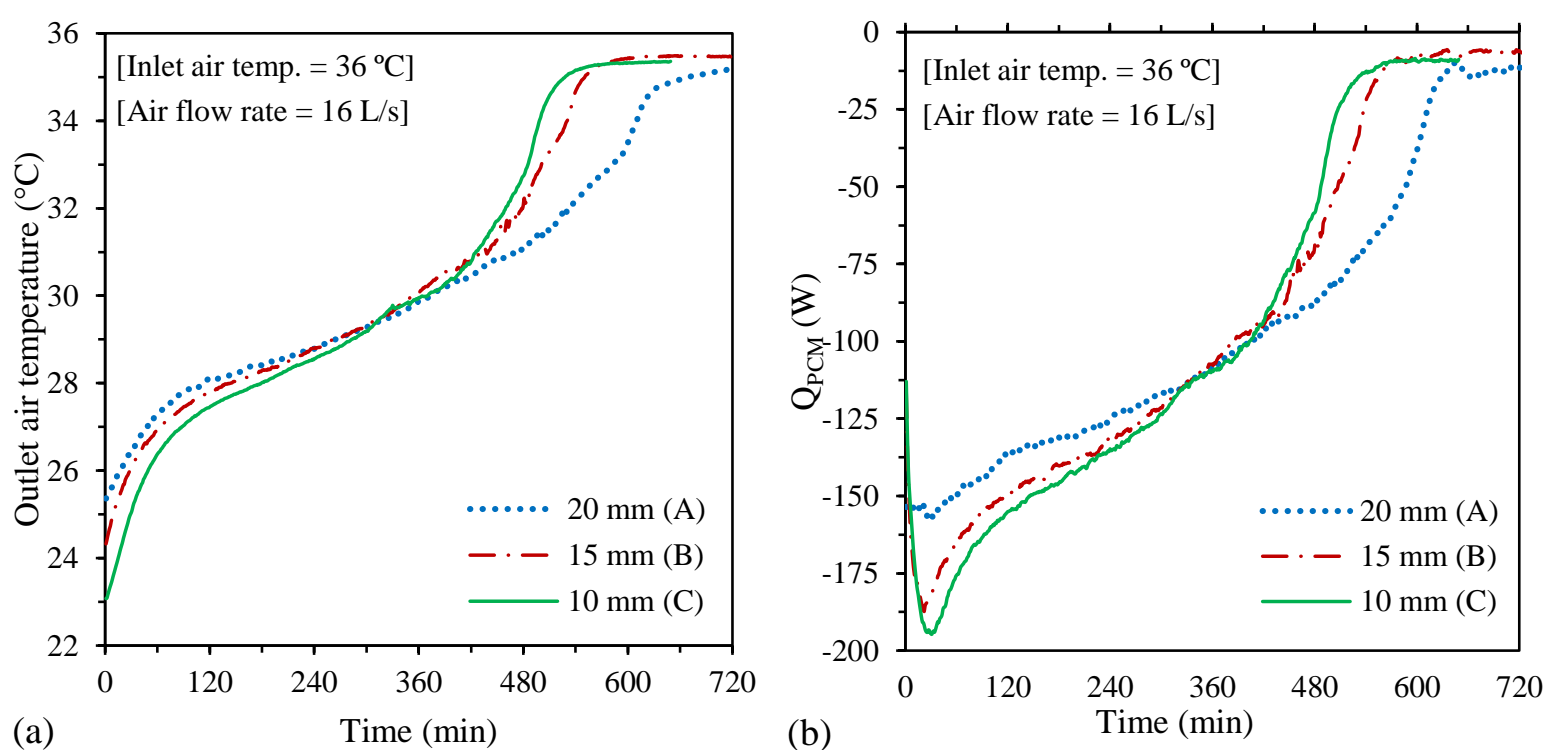

Figure 19: Impact of air channels height on the PCM discharging; variation in (a) the outlet air temperature, and (b) the PCM heating rate.

The melting time and the corresponding comfort periods for the three cases under the adopted operating conditions are illustrated in Figure 20 and Figure 21, respectively. It can be observed that the time required for complete PCM melting and the comfort period prolongs with the air channels height.

As shown in Figure 20a, the increase of melting time with the air channels height varies based on the inlet air temperature. The melting time increase was larger at the low inlet air temperatures compared to the high temperatures. For instance, increasing the height of the air channel from 10 to $20 \mathrm{~mm}$ prolonged the melting time by $26-20 \%$ at inlet air temperatures 32 $40{ }^{\circ} \mathrm{C}$, respectively, when the air flow rate was $16 \mathrm{~L} / \mathrm{s}$. On the other hand, as shown in Figure $20 \mathrm{~b}$, the melting time increase varies with the augment of air channels height depending on the air flow rate. The melting time increase was larger at low air flow rates compared to the high flow rates. As an illustration, with the augment of air channels height from $10 \mathrm{~mm}$ to $20 \mathrm{~mm}$, the melting time has extended by $28-25 \%$ for the air flow rates $7-25 \mathrm{~L} / \mathrm{s}$, respectively when the inlet air temperature was $36^{\circ} \mathrm{C}$.

Figure 21 indicates that the variation in the comfort period for the three tested PCM configurations with different air channel heights was very slight under all tested conditions. This is evident in Figure 19, where the outlet air temperature curves intersect approximately at the maximum comfort temperature of $30{ }^{\circ} \mathrm{C}$. At a given temperature, the variation in comfort time was less than $7 \%$ in all cases, except for the case where the air flow rate was $25 \mathrm{~L} / \mathrm{s}$ (Figure $21 \mathrm{~b}$ ) at which case configuration $\mathrm{C}$ has exhibited a longer comfort time by nearly $20 \%$ compared to the other arrangements. This was attributed to a lower PCM initial temperature by almost $2 \mathrm{~K}$ in case $\mathrm{C}$ at the beginning of the discharging process. 


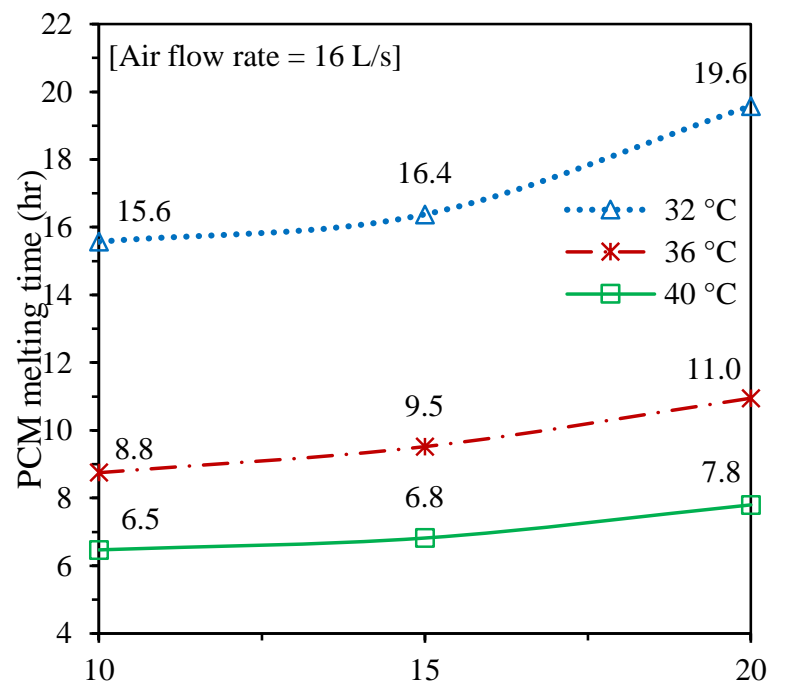

(a)

Air channel height (mm)

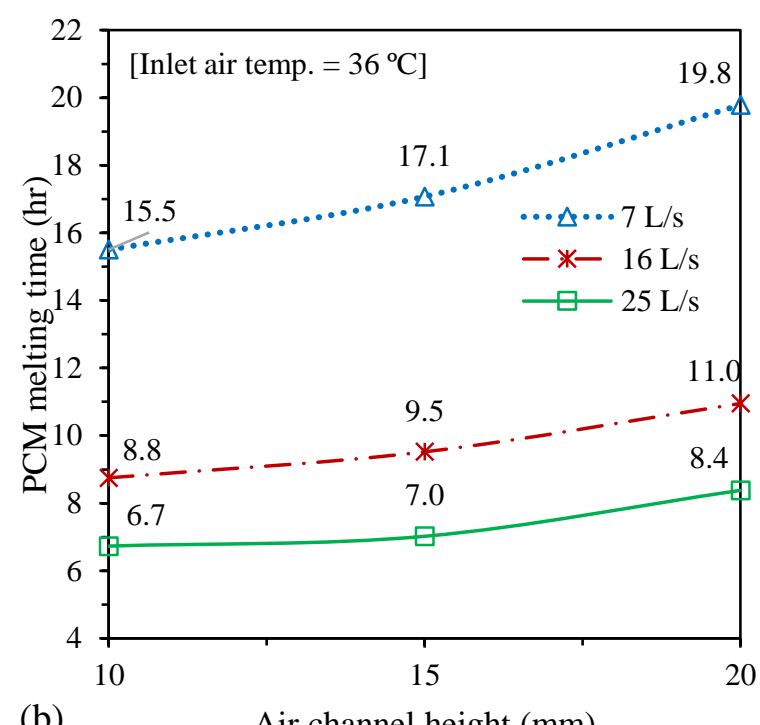

Figure 20: Sensitivity of PCM melting time to the air channels height under various (a) inlet air temperatures, and (b) air flow rates.

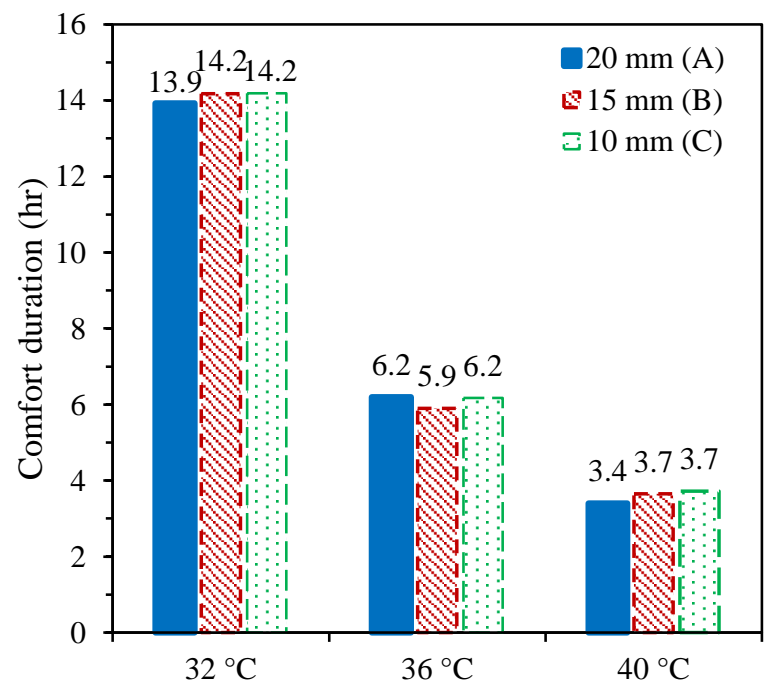

(a) Inlet air temperature $\left({ }^{\circ} \mathrm{C}\right)$

Figure 21: Influence of air channels height on the comfort level period under various (a) inlet air temperatures, and (b) air flow rates.

Significantly, under current TES configurations and PCM transition temperature range, it appears that the distance between the PCM modules has a great impact on the complete discharging of the PCM cooling and a negligible impact on the thermal comfort duration. 


\subsection{Comparison with a numerical study}

A comparison between the experimental results presented in this study and results predicted using a CFD simulation published by the authors in a previous article [42] has been carried out to determine the deviation of the experimental data. The PCM temperature was compared at various locations in the TES unit for both charging and discharging phases, as shown in Figure 22. It can be observed that the numerical and experimental data have followed a similar trend and were in a good agreement. The temperature profile was very smooth in the case of real conditions (experiment), and linearly in the modelling results, owing to the natural variation of the PCM thermo-physical properties with the temperature, which met by constant values assumed in the computational modelling. This justifies the variation during the PCM sensible cooling and heating phases. During the transition phase, the results have shown a maximum deviation of $1.55 \%$ and $1.93 \%$ for the charging and discharging results, respectively. Another reason for the discrepancies can be the inaccuracy of the experimental measurements, as the overall uncertainty of the current experiments was estimated at $\pm 1.12 \%$.
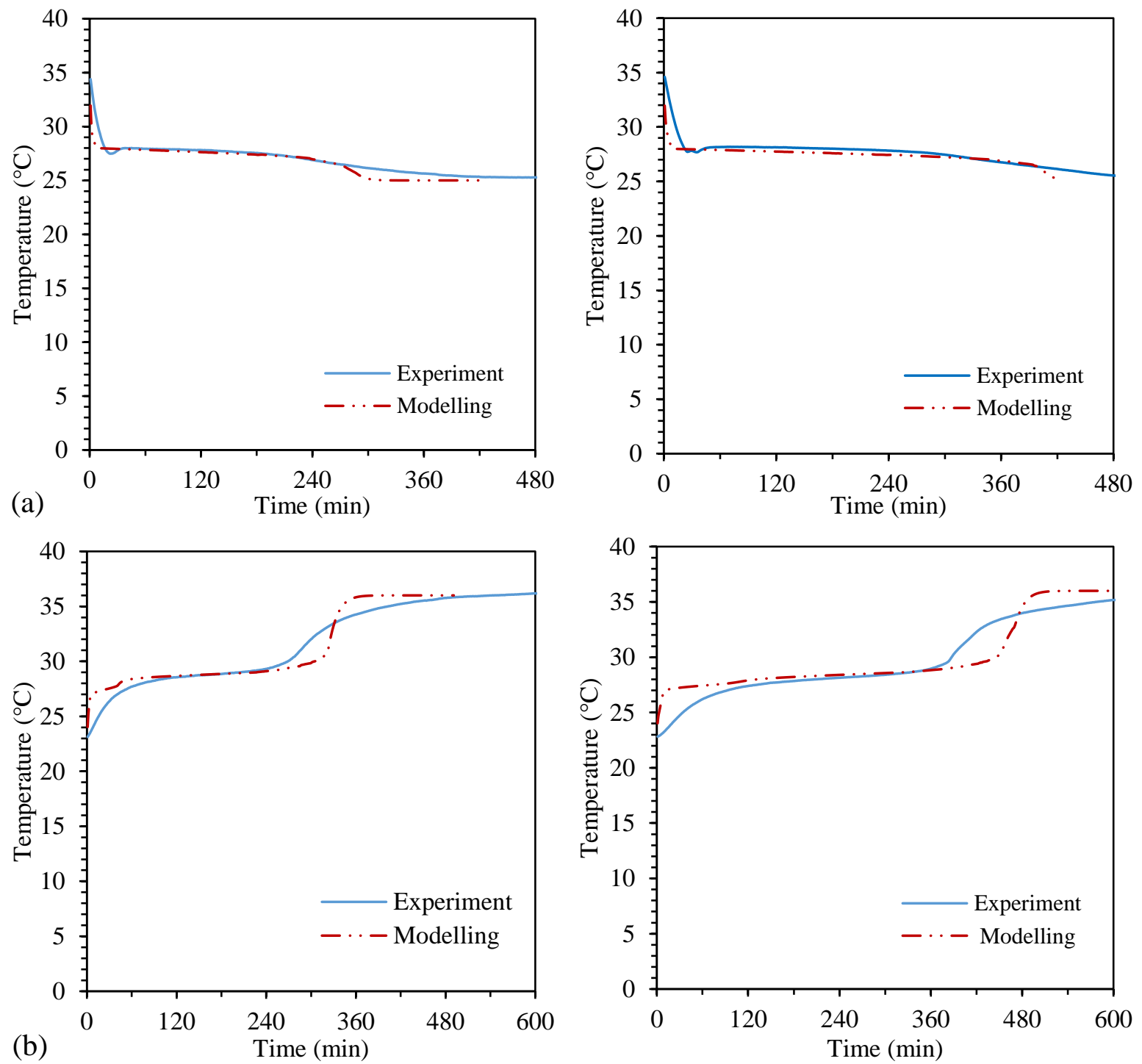

Figure 22: A comparison between numerical and experimental PCM temperatures during the (a) charging, and (b) discharging processes. 


\section{Conclusions}

An experimental investigation of a PCM-air heat exchanger for free cooling of building under hot-arid climate conditions was carried out. The PCM charging and discharging performance were investigated under various inlet operating conditions for different arrangements of PCM modules with varying air flow channels, besides investigating the PCM supercooling during the charging process. Based on the charging and discharging experiments, the following observations have been drawn;

- Inlet air temperature has a significant impact on PCM charging/discharging duration depending on the variation from the PCM liquidus/solidus temperature. Larger variations are advantageous for a quicker charging process, while small variations are desirable to prolong the thermal comfort period during the discharging phase.

- Air flow rate has a great impact on the charging process. Higher air flow rates are recommended to accelerate the PCM solidification. However, the flow rate should be adjusted carefully based on the available charging temperature to harness the most out of the night cooling in the required time with low input power to the fan. In contrast, lower air flow rates may be necessary for gradual coolness extraction from the PCM during the discharging period to maintain longer thermal comfort duration, considering air supply at an adequate velocity to meet the occupants' comfort.

- Optimising the distance between the PCM panels is an important aspect to enhance the system performance. Narrow air flow channels allow higher cooling potential and hence, shorter solidification time during the charging process. On the other hand, a system with wider air channels provides a slower melting rate during the discharging process, whereas the comfort durations are generally not affected by the height of the air channel. Consequently, a compact TES design with narrow air flow channels can be appropriate for both transition phases. However, narrow air channels may induce a high pressure drop and hence, higher fan power consumption.

- The supercooling rate in the selected PCM was relatively small (around $1 \mathrm{~K}$ ). The supercooling is affected by the air flow rate, where it takes a longer time at the low flow rates, and is also affected by the charging air temperature, where it takes a longer time at air temperatures close to the PCM solidus temperature. The results pointed out that the supercooling has led to a solidification delay and had no noticeable impact on the outlet air temperature. Under the tested range of inlet air temperatures and flow rates, it appears that the low supercooling is a positive characteristic for the organic RT28-HC PCM utilised in this research.

Overall, it can be stated that the proposed free cooling system is able to contribute to buildings energy saving under hot-arid climate conditions, and thus, has a potential to minimise the operation hours of the conventional air conditioning systems. 


\section{Acknowledgments}

The authors acknowledge the University of Nottingham in the UK, University of Khartoum in Sudan, and the Ministry of Higher Education and Scientific Research of Sudan for the financial support of this research.

\section{References}

1. Zeinelabdein, R., S. Omer, and G. Gan, Critical review of latent heat storage systems for free cooling in buildings. Renewable and Sustainable Energy Reviews, 2018. 82(Part 3): p. 2843-2868.

2. $\quad$ Boyle, G., Renewable energy. 2004: OXFORD university press.

3. Harjunowibowo, D., et al., Recent active technologies of greenhouse systems - A comprehensive review. Bulgarian Journal of Agricultural Science, 2018. 24(1): p. 158170.

4. Zeinelabdein R., O.S., Mohamed E., Amaireh I., Gan G, Free cooling based phase change material for domestic buildings in hot arid climate, in 16th International Conference on Sustainable Energy Technologies - SET 2017. 2017: Bologna, Italy.

5. Mohamed, E., S. Riffat, and S. Omer, Low-temperature solar-plate-assisted heat pump: A developed design for domestic applications in cold climate. International Journal of Refrigeration, 2017. 81: p. 134-150.

6. Zalba, B., et al., Free-cooling of buildings with phase change materials. International Journal of Refrigeration, 2004. 27(8): p. 839-849.

7. Waqas, A. and Z.U. Din, Phase change material (PCM) storage for free cooling of buildings - a review. Renewable and sustainable energy reviews, 2013. 18: p. 607-625.

8. Raj, V.A.A. and R. Velraj, Review on free cooling of buildings using phase change materials. Renewable and Sustainable Energy Reviews, 2010. 14(9): p. 2819-2829.

9. Dincer, I. and S. Dost, A perspective on thermal energy storage systems for solar energy applications. International Journal of Energy Research, 1996. 20(6): p. 547-557.

10. Sharma, A., et al., Review on thermal energy storage with phase change materials and applications. Renewable and Sustainable energy reviews, 2009. 13(2): p. 318-345.

11. Pasupathy, A., R. Velraj, and R. Seeniraj, Phase change material-based building architecture for thermal management in residential and commercial establishments. Renewable and Sustainable Energy Reviews, 2008. 12(1): p. 39-64.

12. Regin, A.F., S. Solanki, and J. Saini, Heat transfer characteristics of thermal energy storage system using PCM capsules: a review. Renewable and Sustainable Energy Reviews, 2008. 12(9): p. 2438-2458.

13. Turnpenny, J., D. Etheridge, and D. Reay, Novel ventilation cooling system for reducing air conditioning in buildings.: Part I: testing and theoretical modelling. Applied Thermal Engineering, 2000. 20(11): p. 1019-1037.

14. Turnpenny, J., D. Etheridge, and D. Reay, Novel ventilation system for reducing air conditioning in buildings. Part II: testing of prototype. Applied thermal engineering, 2001. 21(12): p. 1203-1217.

15. Iten, M., S. Liu, and A. Shukla, A review on the air-PCM-TES application for free cooling and heating in the buildings. Renewable and Sustainable Energy Reviews, 2016. 61: p. 175-186.

16. Alizadeh, M. and S.M. Sadrameli, Development of free cooling based ventilation technology for buildings: Thermal energy storage (TES) unit, performance enhancement techniques and design considerations - A review. Renewable and Sustainable Energy Reviews, 2016. 58: p. 619-645. 
17. Thambidurai, M., K. Panchabikesan, and V. Ramalingam, Review on phase change material based free cooling of buildings-The way toward sustainability. Journal of Energy Storage, 2015. 4: p. 74-88.

18. Kamali, S., Review of free cooling system using phase change material for building. Energy and Buildings, 2014. 80: p. 131-136.

19. Arkar, C. and S. Medved, Free cooling of a building using PCM heat storage integrated into the ventilation system. Solar Energy, 2007. 81(9): p. 1078-1087.

20. Medved, S. and C. Arkar, Correlation between the local climate and the free-cooling potential of latent heat storage. Energy and Buildings, 2008. 40(4): p. 429-437.

21. Arkar, C., B. Vidrih, and S. Medved, Efficiency of free cooling using latent heat storage integrated into the ventilation system of a low energy building. International Journal of Refrigeration, 2007. 30(1): p. 134-143.

22. Mosaffa, A., et al., Thermal performance of a multiple PCM thermal storage unit for free cooling. Energy Conversion and Management, 2013. 67: p. 1-7.

23. Borderon, J., J. Virgone, and R. Cantin, Modeling and simulation of a phase change material system for improving summer comfort in domestic residence. Applied Energy, 2015. 140: p. 288-296.

24. Yanbing, K., J. Yi, and Z. Yinping, Modeling and experimental study on an innovative passive cooling system-NVP system. Energy and buildings, 2003. 35(4): p. 417-425.

25. Nagano, K., et al., Study of a floor supply air conditioning system using granular phase change material to augment building mass thermal storage-heat response in small scale experiments. Energy and Buildings, 2006. 38(5): p. 436-446.

26. Takeda, S., et al., Development of a ventilation system utilizing thermal energy storage for granules containing phase change material. Solar Energy, 2004. 77(3): p. 329-338.

27. Alam, M., A comparative study on the effectiveness of passive and free cooling application methods of phase change materials for energy efficient retrofitting in residential buildings. 2017.

28. Rajagopal, M., et al., Free Cooling Potential and Technology Options for Thermal Energy Management of a Commercial Building in Bangalore City, India. Energy Engineering, 2014. 111(2): p. 11-24.

29. Panchabikesan, K., et al., Effect of direct evaporative cooling during the charging process of phase change material based storage system for building free cooling application-A real time experimental investigation. Energy and Buildings, 2017. 152: p. 250-263.

30. Panchabikesan, K., et al., Enhancement in free cooling potential through PCM based storage system integrated with direct evaporative cooling (DEC) unit. Energy, 2018. 144: p. 443-455.

31. Jaber, S. and S. Ajib, Novel cooling unit using PCM for residential application. International Journal of Refrigeration, 2012. 35(5): p. 1292-1303.

32. Iten, M. and S. Liu, Experimental Study on the Performance of RT 25 to be Used as Ambient Energy Storage. Energy Procedia, 2015. 70: p. 229-240.

33. Lazaro, A., et al., PCM-air heat exchangers for free-cooling applications in buildings: Empirical model and application to design. Energy Conversion and Management, 2009. 50(3): p. 444-449.

34. Stritih, U. and V. Butala, Energy saving in building with PCM cold storage. International Journal of Energy Research, 2007. 31(15): p. 1532-1544.

35. Darzi, A.R., et al., Numerical investigation of free-cooling system using plate type PCM storage. International Communications in Heat and Mass Transfer, 2013. 48: p. 155163. 
36. Osterman, E., et al., Parametrical analysis of latent heat and cold storage for heating and cooling of rooms. Applied Thermal Engineering, 2015. 84: p. 138-149.

37. Raj, V.A.A. and R. Velraj, Heat transfer and pressure drop studies on a PCM-heat exchanger module for free cooling applications. International Journal of Thermal Sciences, 2011. 50(8): p. 1573-1582.

38. Waqas, A. and S. Kumar, Thermal performance of latent heat storage for free cooling of buildings in a dry and hot climate: An experimental study. Energy and Buildings, 2011. 43(10): p. 2621-2630.

39. Waqas, A. and S. Kumar, Utilization of latent heat storage unit for comfort ventilation of buildings in hot and dry climates. International Journal of Green Energy, 2011. 8(1): p. 1-24.

40. Waqas, A., M. Ali, and Z. Ud Din, Performance analysis of phase-change material storage unit for both heating and cooling of buildings. International Journal of Sustainable Energy, 2015(ahead-of-print): p. 1-19.

41. Muthuvelan, T., et al., Experimental investigation of free cooling using phase change material-filled air heat exchanger for energy efficiency in buildings. Advances in Building Energy Research, 2016: p. 1-11.

42. Zeinelabdein, R., et al., Free cooling using phase change material for buildings in hotarid climate. International Journal of Low-Carbon Technologies, 2018. 13(4): p. 327337.

43. RUBITHERM. [cited 2017, 09/11]; Available from: [〈https://www.rubitherm.eu/>].

44. Oliver, J., The climate of Khartoum province. Sudan notes and records, 1965. 46: p. 90129.

45. Peel, M.C., B.L. Finlayson, and T.A. McMahon, Updated world map of the KöppenGeiger climate classification. Hydrology and earth system sciences discussions, 2007. 4(2): p. 439-473.

46. WMO. World Meteorological Organization. 2016 [cited 2016 12/5]; Available from: http://worldweather.wmo.int/en/city.html?cityId=249

ftp://ftp.atdd.noaa.gov/pub/GCOS/WMO-

Normals/TABLES/REG_I/SU/62721.TXT.

47. Moffat, R.J., Describing the uncertainties in experimental results. Experimental thermal and fluid science, 1988. 1(1): p. 3-17.

48. CIBSE, G.A., Environmental design. The Chartered Institution of Building Services Engineers, London, 2006.

49. Merghani, A., Thermal comfort and spatial variability: a study of traditional courtyard houses in the hot dry climate of Khartoum, Sudan. 2001, University of Cambridge.

50. Nicol, J.F. and M.A. Humphreys, Adaptive thermal comfort and sustainable thermal standards for buildings. Energy and buildings, 2002. 34(6): p. 563-572. 